\title{
Experience and gender effects in acquisition experiment with value messages
}

\author{
D. Di Cagno - A. Galliera - W. Güth • \\ N. Pace $\cdot$ L. Panaccione
}

Accepted: 14 June 2016

(C) Springer Science+Business Media New York 2016

\begin{abstract}
In the bargaining experiment, the privately informed seller of a company sends a value message to the uninformed potential buyer who proposes a price for acquiring the company. Participants are constantly either seller or buyer and interact over 30 rounds with randomly changing partners. How are overstating the value of the company, underpricing the received value message and acceptance of price offers affected by experience and gender (constellation)? We control via treatments for awareness of gender (constellation) and
\end{abstract}

D. Di Cagno $(\bowtie) \cdot$ A. Galliera · W. Güth

Luiss Guido Carli, Rome, Italy

e-mail: ddicagno@luiss.it

A. Galliera

e-mail: agalliera@luiss.it

W. Güth

e-mail: gueth@coll.mpg.de

W. Güth

Frankfurt School of Finance and Management,

Frankfurt am Main, Germany

W. Güth

Max Planck Institute on Collective Goods, Bonn,

Germany

N. Pace

University Ca' Foscari of Venice, Venice, Italy

e-mail: n.pace@unive.it

L. Panaccione

University of Rome Tor Vergata, Rome, Italy

e-mail: luca.panaccione@uniroma2.it show that gender (constellation) matters and that the main experience effects apply across gender (constellations).

Keywords Bargaining - Price signals - Learning · Experiment · Gender · Winner's curse - Take-over bidding

JEL Classifications $\quad \mathrm{C} 78 \cdot \mathrm{C} 91 \cdot \mathrm{D} 83 \cdot \mathrm{J} 16$

\section{Introduction}

Gender effects in small business economics are a familiar topic since the analyses of Daly (1991), Brush (1992), Rosa et al. (1996) but varied in which aspect is considered: mainly self-employment as well as ownership, management and performance. In 1991, Loscocco et al. explain the lower female success by lack of experience and their stronger presence in less profitable industry sectors by structural disadvantages. More recently, the relevance of gender differences in small business economics has been debated in many situations such as competitiveness (Bönte and Piegeler 2013), business creation rate (Minniti and Nardone 2007), size and composition of start-up capital and its use (Verheul and Thurik 2001). The results are not univocal but mainly give rise to the question if gap of experience can explain gender differences. 
Our results confirm some of those field findings but mainly differ in the behavior we study as well as in the empirical method.

What we analyze is framed as acquiring or selling a company and thus renders ownership the crucial endogenous aspect. Rather than comparing management performances across gender, our focus is on bargaining behavior in situations with incomplete information (only sellers know the values of their firms) and common evaluation (sellers' and buyers' evaluations are perfectly correlated) and behavior in both roles (potential buyer and potential seller).

Regarding the empirical method, we clearly differ by relying on experimental rather than survey data (like Arentz et al. 2013, who test of the role of prior knowledge in entrepreneurial discovery). However, our results, i.e., that experience more than gender matters, are in line with both some of the earlier and the more recent economic contributions.

In our stylized experimental setup, acquisition decisions are analyzed in the form of take-over bidding, i.e., as "take-it-or-leave-it" offer bargaining, where unlike to most other such bargaining experiments (see Güth and Kocher 2014, for a recent review) we allow for a privately better informed seller. We investigate the differences between inexperienced and experienced participants analyzing cheap talk value signals, experience and gender in a bargaining experiment: the privately informed seller of a company sends a value message to the uninformed potential buyer who then proposes a price (a take-over bid) for acquiring the company. ${ }^{1}$ To do so, the Acquiring-aCompany game (Samuelson and Bazerman 1985) is modified by an initial (cheap talk) value message from the privately informed seller to the buyer, before the take-it-or-leave-it price offer to the seller.

Cheap talk is usually experimentally implemented via more or less restricted pre-play communication and has been shown to improve coordination (see for an early survey Crawford 1998), e.g., in game experiments with multiple equilibria, and to crowd out costly punishing, e.g., in ultimatum game experiments, where it represents a less costly alternative for expressing own anger or disappointment. Cheap talk

\footnotetext{
$\overline{1}$ As already mentioned, our analysis neglects antitrust regulation to prevent acquisitions which would question market competition and thereby harm customers (see for such regulation Posner 2009).
}

may reduce or even resolve the problem of asymmetric information which can lead to no-trade results as in markets for lemons (Akerlof 1970) and in the Acquiring-a-Company game (Samuelson and Bazerman 1985). Compared to such communication, value messages which can be false or true are also "cheap" but hardly qualify as "talk." To the best of our knowledge, little research has been directed toward the role of such "value stating" cheap talk in bargaining experiments with private information and control of experience and gender (constellation). ${ }^{2}$

Although several studies investigate gender differences in preferences and behavior, ${ }^{3}$ very few jointly focus on experience and gender (constellation). Casari et al. (2007), who study the winner's curse in common value auctions ${ }^{4}$ to understand how experienced bidders learn to avoid it, find that women are much more susceptible to the winner's curse as inexperienced bidders than men with this difference disappearing for experienced bidders. Their estimates also show that women learn much faster than men: they start out bidding much worse only to close much of the gap in the final periods; this is also confirmed by Ham and Kagel (2006) and Ortmann and Tichy (1999) for a prisoner's dilemma-type game who find women cooperating significantly more than men in early rounds with this difference disappearing in the later rounds. Regarding the effects on gender constellation for which we also control we refer to Sutter et al. (2009) who especially alert to equal gender constellations.

\footnotetext{
${ }^{2}$ Considering such true or false reporting and gender, Dreber and Johannesson (2008), as well as Erat and Gneezy (2011) and Gneezy (2005), find that men are more likely to lie for a monetary gain than women and Houser et al. (2012) observe that men are more likely to incorrectly report the result of a private coin flip than women (unlike in bargaining such false reporting does not harm another participant but the experimenter), yet they do not investigate whether those gender differences in cheap talk persist when controlling for experience.

${ }^{3}$ Croson and Gneezy (2009) provide an extensive overview of gender differences documented in studies on risk attitude, social preferences (ultimatum and dictator games, trust and reciprocity, prisoner's dilemmas, social dilemmas and public good provision) and competitive behavior.

${ }^{4}$ Without considering cheap talk value messages for which we allow in our experiment, but which are rarely studied in auction experiments (see Kagel and Levin 2014).
} 
Without discussing the usual (dis)advantages of experiments in empirical research like their questionable internal and external validity but better control of institutional aspects like market rules, information and (material) incentives we readily acknowledge that experience will probably matter a lot but that control of gender (constellation) and, for the ease of comparison, of "field of study" (constellation) seems a bit awkward. Nevertheless, in a hierarchically organized enterprise or owner-run small business, the gender of the one being finally responsible for (merger and) acquisition may be decisive. In such case, commonly known gender (constellation) is admittedly special but not very unrealistic. Note also that, although we explore experience effects, we try to preserve the oneoff aspect of acquisition bargaining by (random) strangers matching and by paying only one random round (see Sect. 3 for more details on the experimental protocols).

Our conjectures about behavior (acceptance of price offer, prices offered and value messages) are shaped by the initial one-round findings, reported in our companion paper (Di Cagno et al. 2016) what explains that we do not state and test (so far unexplored) hypotheses. Nevertheless it is, in our view, crucially important to assess how effects for inexperienced participants survive when becoming much more familiar with the setup and when gaining more and more experience when assuming that random rematching and asymmetric information justify our one-off interaction benchmark analysis.

In our setting, as in a signaling game, the uninformed buyer might infer some information from the value message about the true value of the firm owned by the seller. However, sellers of low value firms should also send high value messages: in the suggestive terminology of Erat and Gneezy (2011) this suggests "selfish black lies" to which we will refer in our context as "making-up" (the value of the firm). ${ }^{5}$ Therefore, only pooling equilibria emerge with the same uninformative (high) value messages sent by sellers.

This game-theoretic rigor, used to establish only pooling equilibria or, in other words, to disqualifying the value message as "cheap talk," is due to the strict rules of social exchange: the one sided value message

\footnotetext{
5 According to our data "selfish black lies," however, coexist with significant and persistent understating and truth-telling.
}

of the seller to the buyer is one social exchange before the buyer states the take-it-or-leave-it price offer. This differs from the study of Valley et al. (1998) who also allow for social exchange in the context of Acquiringa-Company, only in different face communication formats (face-to-face bargaining, written negotiation exchange, telephone negotiations). This obviously excludes strict game-theoretic reasoning but, as expected, is quite efficiency enhancing with the strongest effect, with respect to fair surplus sharing, for face-to-face negotiations. Here we wanted to maintain the strict strategic format by implementing the Modified Acquiring-a-Company ${ }^{6}$ setup as a Bayesian game as much as possible, thus allowing for many repetitions-which would be difficult for the Valley et al. (1998) setup- and restricting identifiability of one's interaction partner to either gender or field of study, or both. As such we feel that we are, to the best of our knowledge, pioneering in jointly analyzing the three dimensions involved in our study, namely cheap talk, gender (constellation) and experience.

According to our companion study Di Cagno et al. (2016), based on a single incentivized play of this game, it is found that value messages positively and significantly increase price offers. Will experience strengthen or weaken this effect? We expected the latter, i.e., convergence to pooling. Although one interacts with randomly changing trading partners in the other role, repetitive play may trigger reputation concerns, e.g., in the form of role (a participant is constantly either a potential seller or buyer) or of gender solidarity. Of course, such reputation effects are unlikely in stochastic games, especially those with private information. On the other hand, trade is always efficiency enhancing and at least some seller participants might be intrinsically motivated to signal the true value.

For the same experimental setting, we have collected data from participants interacting over 30 rounds (with fixed role of either seller or buyer and randomly changing partners in the other role) to test how overstating the value of the company, underpricing the received value message and acceptance of price offers are affected by experience and gender (constellation). By comparing three successive phases

\footnotetext{
${ }^{6}$ Valley et al. (2002) compare such free format replay communication and a no communication control treatment for situations with two-sided incomplete information.
} 
consisting of 10 rounds each, labeled early phase (rounds 1-10), intermediate phase (rounds 11-20) and late phase (rounds 21-30), we will analyze how experience shapes acceptance of price offers, price offers and value messages where our focus is on experience effects but not on individual learning (for a review of experiments on individual learning, see Camerer 2003).

Quite surprisingly, a constant positive share of seller participants invests in role reputation by not overstating (their firm's value) with a relevant heterogeneity in not "making-up" within and across the three phases with 10 successive rounds each. ${ }^{7}$ Concerns for role reputation thus exist but only for a minority of experimental traders.

It seems to depend on intrinsic motivation and social dynamics ${ }^{8}$ whether behavior converges to pooling or whether some trust in value messages pertains, possibly together with price offers aiming at fair surplus sharing. Of course, one might appeal to other regarding concerns (one may want to distinguish oneself from other seller participants with excessively large signals or compensate harm caused by other price offers). However, in a context with private information it seems far easier to achieve such effects via truth-telling, i.e., by not lying.

Our results offer data:

1. for seller participants: mainly overstating ("making-up") but also truth-telling and understating (the value of one's firm) as well as (non) acceptance of (non) profitable price offers,

2. for buyer participants: price offers which are systematically lower than the value message received ("suspicion" or "equal surplus sharing" or weaker forms of letting both sides gain) and based on more or less trust in value messages,

3. for gender (constellation): according to which female acceptance is to a greater extent influenced by experience than the male one, in suspiciousness gender constellation seems to interact with path dependence for females (female buyers are

\footnotetext{
$\overline{7}$ A significant share of participants frequently and persistently signals the value consistent with truth-telling what, however, does not suffice that buyer participants, who often and repeatedly experience false signals, will trust in "Kantian imperatives."

${ }^{8}$ We refrain from postulating convergence of the interacting dynamics after 30 rounds.
}

more suspicious when confronting male sellers) and gender difference co-evolves with "makingup" (female sellers are only significantly less overstating than males in the early phase). An obvious hypothesis claims gender (constellation) effect to be considerably weakened or even eliminated by game playing experience and suggests that gender (constellation) effects mainly rely on data of inexperienced decision making. Since treatments partly allow for commonly known gender constellations, this does not only apply to conditioning behavior on own gender but also on another's gender.

"Making-up" and "suspicion" persist, gender (constellation) effects seem to be rather paradigmatic, given the different tasks and skills of human males and females in our evolutionary history (see also the related discussion in our companion paper). In our view, gender research has thus far neglected the aspects on which we focus on.

Finally, it hardly needs to be justified that "makingup" (consider not only commercial but also private life, e.g., when searching a spouse) and "suspicion" (in commercial and private life we often doubt what others can offer) are important. Altogether it seems very interesting and informative to compare behavior of inexperienced and experienced participants, who both matter economically, e.g., when designing spot markets whose traders change frequently, respectively, when establishing institutions which are to be encountered repeatedly.

The paper develops as follows: Sect. 2 introduces the modified game. Section 3 describes the experimental protocol. Descriptive statistics are discussed in Sect. 4. Section 5 provides the regression analysis. Section 6 concludes. Appendix 1 (Tables) and Appendix 2 (English Translated Instructions) follow.

\section{Game model}

The buyer's value $v$ of the firm, owned by the seller, is randomly generated according to the uniform density concentrated on $(0,1)$. This is commonly known along with the fact that for the seller the value of the firm is only $q v$, with $0<q<1$. If trade occurs at price $p$, the buyer earns $v-p$ and the seller $p-q v$. The decision process in each round is as follows: 
(i) knowing $v$, the seller sends the value message $\hat{v}=\hat{v}(v)$ which might be true $(\hat{v}=v)$ or false $(\hat{v} \neq v)$;

(ii) after receiving the message $\hat{v}$, the buyer proposes the price $p=p(\hat{v})$;

(iii) after receiving the price offer, the seller accepts it $(\delta(p)=1)$ or rejects it $(\delta(p)=0)$.

The seller earns $\delta(p)(p-q v)$ and the buyer $\delta(p)$ $(v-p)$ : when trading, i.e., when $\delta(p)=1$, the total surplus $v(1-q)$ is always positive. When not trading, i.e., when $\delta(p)=0$, both buyer and seller earn nothing.

Since $\delta(p)=1$ is only optimal for $p \geq q v$, a risk neutral buyer expects to earn

$$
\int_{0}^{p / q}(v-p) \mathrm{d} v=(0.5-q) \frac{p^{2}}{q^{2}}
$$

which increases (decreases) with $p$ for $q<0.5(q>0.5)$. Since $v<1$ implies $v q<q$, it is never optimal for the buyer to offer a price higher than $q$ : the price $p=q$ is optimal for $q \leq 0.5$, whereas trade is avoided by $p=0$ for $q>0.5$. This benchmark solution is not questioned by cheap talk.

The Acquiring-a-Company game is a convenient experimental workhorse designed to study the winner's curse, even when allowing for cheap talk. Indeed, buyer participants may fail to anticipate that positive price offers are accepted only if $v \leq p / q$. This then might induce them to offer prices $p$ which yield -assuming $\delta(p)=1$ whenever $p \geq q v$-less than predicted. Of course, the benchmark solution denies the existence of a winner's curse. How is the benchmark solution, based on buyer's risk neutrality and backward induction, then questioned when (i) the seller may be averse to overstating, i.e., to send a value message $\hat{v}(v)>v$ and (ii) the buyer may or not be aware of the seller's moral concerns? The game-theoretic approach would investigate these modifications via a signaling game with the better informed (about the firm's value as well as their own guilty feelings) seller moving first so that the uninformed buyer can possibly infer the firm's value from the value signal $\hat{v}$ : an interesting analytic exercise but an extremely unrealistic one since the seller's idiosyncratic feelings of guilt will never be common knowledge.

\footnotetext{
9 The common priors assumption in the tradition of Harsanyi (1967-1968) is philosophically interesting, and possibly informative, but very unrealistic.
}

Still one might want to speculate how behavior is affected when - at least some-seller participants are feeling obliged to tell the truth. When expecting this, buyer participants may believe the message $\hat{v}$ and suggest a price between $q \hat{v}$ and $\hat{v}$. Quite fairnessminded buyer participants might even propose the price $p(\hat{v})=\frac{(1+q) \hat{v}}{2}$ in order to share the surplus from trade $(1-q) \hat{v}$ equally: actually quite a number of seller participants feel obliged to choose $\hat{v}(v)=v$, with many price offers lying between $q \hat{v}$ and $\hat{v}$. However, cheap talk value messages more frequently induce opportunistic sellers to try to exploit buyers by "making-up" via $\hat{v}(v)>v$ and this, in turn, questions buyers' trust in the message sent by their seller. We expected that because of learning most participants will not trust the value messages which also discourage attempts to share the surplus (more or less) equally. This denies cyclic adaptations, e.g., in the sense of trustworthiness $(\hat{v}(v)$ close to $v)$ and trusting $(p(\hat{v})>\hat{v})$ first evolving, then eroding before again recovering.

Before turning to the experimental design let us comment on the recent debate on other regarding concerns, often described as social preferences (see Cooper and Kagel 2013, for a survey), and of ethical restrictions in decision making, e.g., in the form of (intrinsic) costs of lying (see, for instance Kartik 2009). To the best of our knowledge, the supporting evidence for such concerns so far is nearly exclusively restricted to one-off interactions, what renders any attempt to model the dynamics of other regarding as well as of ethical concerns as speculation without facts. Of course, many efficiency minded participants tried to implement trade, both when theoretically predicted and when not, since it is efficiency enhancing. Similarly, as already mentioned, a significant minority of sellers participants abstained from "making-up." But nearly all participants displayed interpersonal heterogeneity by sometimes being morally guided and sometimes not where this partly depends on the choice task. ${ }^{10}$ In our view, we should first establish stylized facts about moral dynamics in stochastic interaction context before prematurely trying to model it.

\footnotetext{
${ }^{10}$ Seller participants, for instance, hardly ever accepted a minor loss even when being aware that trade is very profitable for the buyer.
} 


\section{Experimental protocol}

We refer here to the part (labeled Phase II in the Instructions) of our broader experimental project that allows us to analyze experience and gender effects. ${ }^{11}$ This stage consists of playing the same bargaining game for 30 rounds and has been preceded by one incentivized trial round which should allow our participants to understand their decision tasks in the following 30 rounds. $^{12}$ In line with the one-off interaction assumption of the analysis in Sect. 2, we implemented random strangers matching. The relatively large (mostly 16) number of participants in the other role in a given session as well as the private information seemed sufficient to discourage attempts of individual reputation formation. We ran 12 sessions with a total of 376 students (11 sessions with 32 participants each plus one session with 24) in the laboratory of Max Planck Institute of Economics in Jena, recruited among the undergraduate population of Jena University with the help of Orsee (Greiner 2004), e.g., to guarantee gender balanced sessions. The experiment was fully computerized using $\mathrm{z}$-Tree (Fischbacher 2007).

At the beginning of the experiment, each participant is randomly assigned to one of the two possible roles (seller or buyer) and remains in this role throughout the experiment: half of the participants are buyers; the other half sellers. Without being made aware of this, half of the sellers and buyers were male and the other half females. In each round, participants were randomly matched with a partner in the other role in order to possibly trade the firm owned by the seller. The value of the firm $v$, randomly selected for each seller-buyer pair according to a discrete uniform distribution concentrated on $(0,100)$, is told only to the seller (the actual values in the experiment, selected in steps of 5 , were $5,10, \ldots, 95$ ). Both (seller and buyer) are aware of the proportion $(q)$, correlating the true evaluations $v$ and $q v$ linearly. This proportion $q$ is randomly selected from a discrete uniform distribution $(0,1)$; the actual values $q$ in the experiment were rescaled in percentages and could only assume the

\footnotetext{
11 The English translation of the Instructions of the whole experiment is reported in Appendix 2.

12 For the results of the incentivized trial round, we refer to Di Cagno et al. (2016).
}

following values: $10,20,30,40,50,60,70,80$ or 90 percent.

In each round (see Table 1), bargaining proceeds in the following way: the seller sends a value message $(\hat{v})$ to the buyer which can be true or false but not exceed 100. After receiving the message, the buyer proposes a price $p$ which cannot exceed 100. Having received the price offer, the seller can accept it or not. If accepted, the firm is sold at the offered price; if not, no trade takes place. After each round, payoffs are calculated and privately communicated to buyer and seller.

\subsection{Treatments}

We ran four treatments differing in information only: in treatment $U$ (Unknown), trading partners, randomly matched in pairs, are unaware of the others gender, which becomes known in treatment $G$ (awareness of Gender constellation). Treatment $O C$ (Other Confound) provides information about the field of study instead (Economics versus Non-Economics). Finally, treatment $E$ (Embedded gender constellation) provides information about the other's gender and field of study. With the last treatment, we try to check possible demand effects of informing about gender (constellation) since, when embedded, one can feel obliged to respond to gender as well as to field of study (constellation), respectively to only one or none of the two.

\subsection{Matching}

Random matching between buyers and sellers was implemented to balance our sample by gender constellation. Pairs occurred in equal proportion: male buyer/female seller, male buyer/male seller, female buyer/male seller and female buyer/female seller. Participants were reminded in each round that they have been randomly paired.

The matching was technically implemented by recruiting as many male as female participants. Furthermore, at the beginning of each session subjects answered (via computer) a short questionnaire asking for gender, field of study (economics vs non-economics), age (above or below 25), level of education (graduate vs undergraduate), smoking habits. Based on this information, the computer assigned roles to participants (seller vs buyer) as to generate pairs in equal proportion. 
Table 1 Road map of game rounds

\begin{tabular}{|c|c|c|c|}
\hline Step $^{a}$ & Seller & Buyer & Description \\
\hline 0 & $q, v$ known partner information ${ }^{\mathrm{b}}$ & $q$ known partner information ${ }^{\mathrm{b}}$ & Initial information provided to buyers and sellers \\
\hline 1 & Message $\hat{v}$ & $\mathrm{c}$ & Seller sends message to buyer \\
\hline 2 & c & Price offer $p(\hat{v})$ & Buyer makes price offer \\
\hline 3 & Acceptance $\delta(p)$ & c & Seller accepts or refuses price offer \\
\hline 4 & Payoff $\delta(p)(p-q v)$ & Payoff $\delta(p)(v-p)$ & Seller and buyer informed on payoff \\
\hline
\end{tabular}

a Each round involves four-steps

b Partner information depends on the treatment, see Sect. 3.1

c Participants wait for partner's decision, i.e., they are inactive

\subsection{Payment}

At the end of each round, participants were informed about their final payoff for that round (in ECU). The conversion rate from experimental points to euro $(1$ euro $=30 \mathrm{ECU})$ was announced in the instructions. If the seller accepted the offered price, the buyer earned the difference between the value of the firm and the price $(v-p)$ and the seller the difference between the accepted price and her evaluation of the firm $(p-q v)$. If the price was not accepted, the final payoff for both was zero. Participants received an initial endowment of 300 ECU (10 euro) in order to avoid bankruptcy. The actual payment was based on one randomly selected round.

\section{Descriptive statistics}

We analyze here how experience affects (i) acceptance of price offers, (ii) price offers $p$ and suspicion $\hat{v}-p$, (iii) value messages $\hat{v}$ and "make-up" $\hat{v}-v$ by comparing three successive phases consisting of 10 rounds each and labeled early phase (rounds 1-10), intermediate phase (rounds 11-20) and late phase (rounds 21-30).

\subsection{Sellers' acceptance}

We consider three intervals for price offers, depending on who gains, respectively, suffers a loss from acceptance: $p \leq q v$ so that buyers gain and sellers suffer a loss; $q v<p<v$ when both, sellers and buyers, gain; $p \geq v$ so that sellers gain and buyers lose (see Fig. 1). Figure 2 illustrates the offers by phase and the

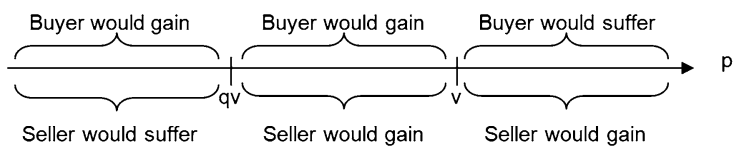

Fig. 1 Intervals of price offers

probability of acceptance for the three price intervals. In particular, vertical bars refer to price offers and horizontal lines refer to share of accepted offers within the range as reported in Table 2; this means, for instance, that $34.31 \%$ of price offers are in $p$ range 2 in Early phase and $89.3 \%$ are accepted in this range in Early phase. Table 2 reports also separately for each phase the probability of acceptance by gender which varies more with phase than with gender.

The share of nearly always accepted price offers with $p \geq v$ is decreasing across phases from 31.06 to $22.71 \%$. The share of mostly refused price offers with $p \leq q v$ increases across phases from 34.63 to $45 \%$ (see Fig. 2).

The gender effects are more subtle. In Table 2, we compare gender with respect to responses averaged over the ten rounds of each phase. We implement a two-paired-sample test of proportions. This table shows that for male sellers, the probability of refusing an offer with $p \geq v$ is close to zero in every phase, whereas for female sellers, it is slightly higher in each phase and decreases across phases. For male sellers, the probability of accepting an offer with $p \leq q v$ is non-negligible and slightly decreasing across phases from 4.66 to $3.53 \%$; for female sellers, this probability is higher in the early phase and lower in the late phase (see first row of Table 2).

Gender difference is never significant and tends to disappear in the late phase, mainly due to female sellers who seem to be more influenced by experience: 
Fig. 2 Price offers by phase. Notes $p$ range 1 $p \leq q v ; p$ range $2 q v<p<v$; $p$ range $3 p \geq v$. Vertical bars refer to price offers and horizontal lines refer to share of accepted offers, within each vertical bar as reported in Table 2

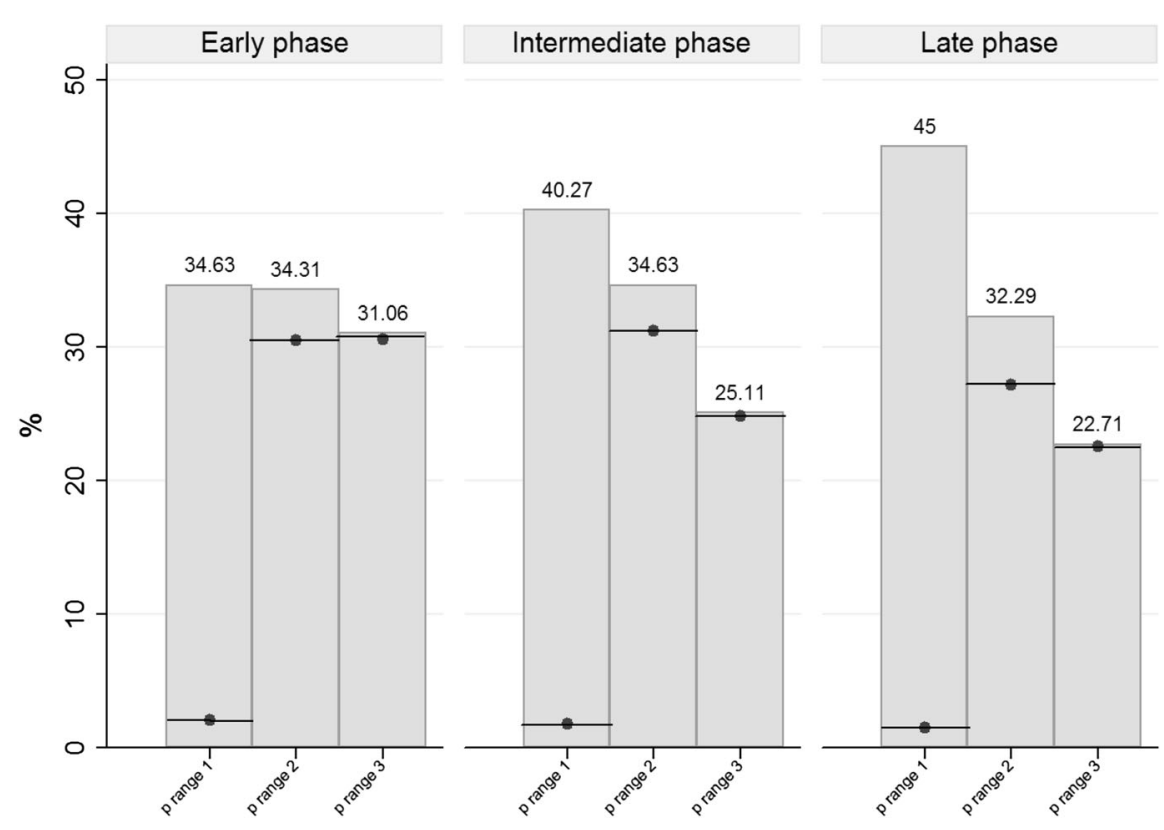

Table 2 Probability of acceptance

\begin{tabular}{|c|c|c|c|c|c|c|c|c|c|c|c|c|}
\hline & \multicolumn{3}{|c|}{ Early phase $^{\mathrm{a}}$} & \multicolumn{3}{|c|}{ Intermediate phase ${ }^{a}$} & \multicolumn{3}{|c|}{ Late phase $^{\mathrm{a}}$} & \multicolumn{3}{|c|}{ Two sample test of proportions } \\
\hline & $\mathrm{F}$ & M & Both & $\mathrm{F}$ & M & Both & $\mathrm{F}$ & M & Both & $\mathrm{F}$ & M & Both \\
\hline$p \leq q v$ & 6.99 & 4.66 & 5.84 & 4.44 & 4.28 & 4.36 & 2.85 & 3.53 & 3.19 & & & \\
\hline$p$ value & $(0.24)$ & & & $(0.91)$ & & & $(0.57)$ & & & $(0.01)$ & $(0.44)$ & $(0.01)$ \\
\hline$d f$ & 649 & & & 755 & & & 844 & & & 748 & 745 & 1495 \\
\hline$v>p>q v$ & 88.72 & 89.91 & 89.3 & 89.84 & 90.48 & 90.17 & 82.15 & 86.13 & 84.18 & & & \\
\hline$p$ value & $(0.63)$ & & & $(0.79)$ & & & $(0.18)$ & & & $(0.02)$ & $(0.15)$ & $(0.01)$ \\
\hline$d f$ & 643 & & & 649 & & & 605 & & & 623 & 625 & 1250 \\
\hline$p \geq v$ & 97.88 & 99 & 98.46 & 97.93 & 99.57 & 98.73 & 99.1 & 99.51 & 99.3 & & & \\
\hline$p$ value & $(0.21)$ & & & $(0.11)$ & & & $(0.96)$ & & & $(0.28)$ & $(0.53)$ & $(0.22)$ \\
\hline$d f$ & 488 & & & 392 & & & 354 & & & 503 & 504 & 1009 \\
\hline
\end{tabular}

$d f$ degrees of freedom

a Test for difference in proportions by gender within stage. $p$ values in brackets

b Test for difference in proportions between early and late phase for males, females and pooled observations. $p$ values in brackets

female sellers mostly decrease the acceptance rate significantly through time, whereas for male sellers it is constant (consistently, the test for difference in means of Table 2 is significant only for female seller). Furthermore, acceptance behavior is not influenced by other regarding preferences: there is no or little evidence of "altruistically minded" sellers rejecting high price offers to protect buyers from losses or of acceptance of welfare enhancing price offers in the range $p \leq q v$ by which only the buyer can gain.
The share of price offers from which both sellers and buyers gain are fairly constant across phases with the probability of accepting them declining over time. Time lapses to accept price offers decline across rounds, revealing clear experience effects for both, female and male sellers. Moreover, the time lapse is shorter when it is obvious to accept $(p \geq v)$ than when it is obvious to refuse (when $p \leq q v$ ). When both, sellers and buyers, would gain the time lapse become longer (see Appendix 1, Table 11). 


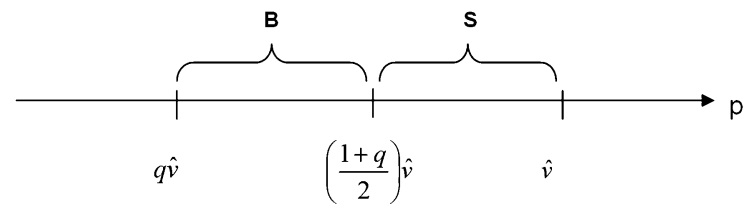

Fig. 3 Regions of price offers

Result 1 Acceptance of price offers yielding a loss for the seller is rare and decreases with experience. Moreover, sellers do not protect buyers who would lose by trading. Gender differences in acceptance behavior are never significant although female sellers mostly reduce their acceptance rate through time.

\subsection{Price offers and suspicion}

Price offers partly express how buyers want to share the surplus from trade and partly reveal suspicion regarding the value message received. For instance, price offers when $q \hat{v}<p<\hat{v}$ could reveal trust in the value message. Moreover, when $\hat{v}(v)=v$, offering $p=\frac{(1+q)}{2} \hat{v}$ would imply equal sharing offers higher (lower) than $\frac{(1+q)}{2} \hat{v}$ and would let sellers (buyers) gain more (see Fig. 3). As is evident, price offers $p \leq q \hat{v}$ clearly reveal suspicion: since truth-telling sellers would reject them, buyers should propose them only when expecting the message to overstate the value of the firm. ${ }^{13}$

Figure 4 shows the distribution of price offers by phase and range of $q$. There is substantial evidence that buyers are suspicious and demand higher surplus shares, which increases over time (represented by $p$ range 1 in Fig. 4). However, there are no relevant gender differences (Table 3).

Furthermore, we use decision time to check for differences in the cognitive process of female and male participants. Although we do not appeal to the usual interpretation of fast emotional and slower deliberated choice making (see Kahneman 2013), it still can be reasoned that a buyer participant confronting repeatedly only or mostly very high and thereby overstating value signals will be annoyed and react more quickly by low price offers. Decision time decreases for both female and male buyers and lapses

$\overline{13}$ Except for noise, we do not expect buyers to offer $p \geq \hat{v}$. for price offers for $p \leq q \hat{v}$, which are shorter than those with $p>q \hat{v}$. Decision lapses for offers in the range $(q \hat{v}, \hat{v})$ are longer. Interestingly, male buyers need more time when demanding more for themselves, i.e., when offering $p>\frac{(1+q) \hat{v}}{2}$, whereas female buyers need more time when demanding less for themselves (see Appendix 1, Table 12).

Result 2 Buyers become more suspicious with experience and more frequently offer prices lower than $q \hat{v}$ which a truth-telling seller should find unacceptable.

\subsection{Value messages and "Make-Up"}

Sellers make up, i.e., choose $\hat{v}>v$ in most cases (Fig. 8 in Appendix 1 shows the difference between $\hat{v}$ and $v$ by phase), even though there is significant evidence of truth-telling and surprisingly strong evidence of understating. Table 4 shows that the share of understating value messages monotonically decreases across phases, whereas the shares of truthtelling and overstating value messages increase.

Moreover, male sellers are generally more sincere than females sellers: the share of true messages by male sellers increases across phases, reaching in the last phase nearly the $20 \%$ of their messages, while the share of true messages sent by female sellers remains fairly stable (nearly $16 \%$ in the last phase).

Decision time shows a strong experience effect: it steadily decreases across phases. As expected, truthtelling is faster than strategizing, with male sellers thinking longer than female ones when overstating (see Table 13 in Appendix 1).

If truth-telling is due to ethical obligations, one should expect the same seller participants to mainly choose $\hat{v}(v)=v$. Otherwise, truth-telling could be due to the occasional investing in the informativeness of value message $\hat{v}^{14}$ The transition matrix in Table 5 reports relative frequencies of seller participants who are truth-telling $i=0 ; 1 ; 2 ; 3 ; 4 ; 5$ or more times, respectively, in one phase and truth-telling $j=0 ; 1 ; 2 ; 3 ; 4 ; 5$ or more times in the following phase. Except for those, who never tell the truth, and

\footnotetext{
${ }^{14}$ In Fig. 5 we report the frequencies of truth-telling by phase and by gender.
} 
Fig. 4 Price offers by phase. Notes $p$ range 1 $p \leq q \hat{v} ; p$ range 2 $\frac{(1+q) \hat{v}}{2}>p>q \hat{v} ; p$ range 3 $\frac{(1+q) \hat{v}}{2} \leq p<\hat{v} ; p$ range 4 $p>\hat{v}$
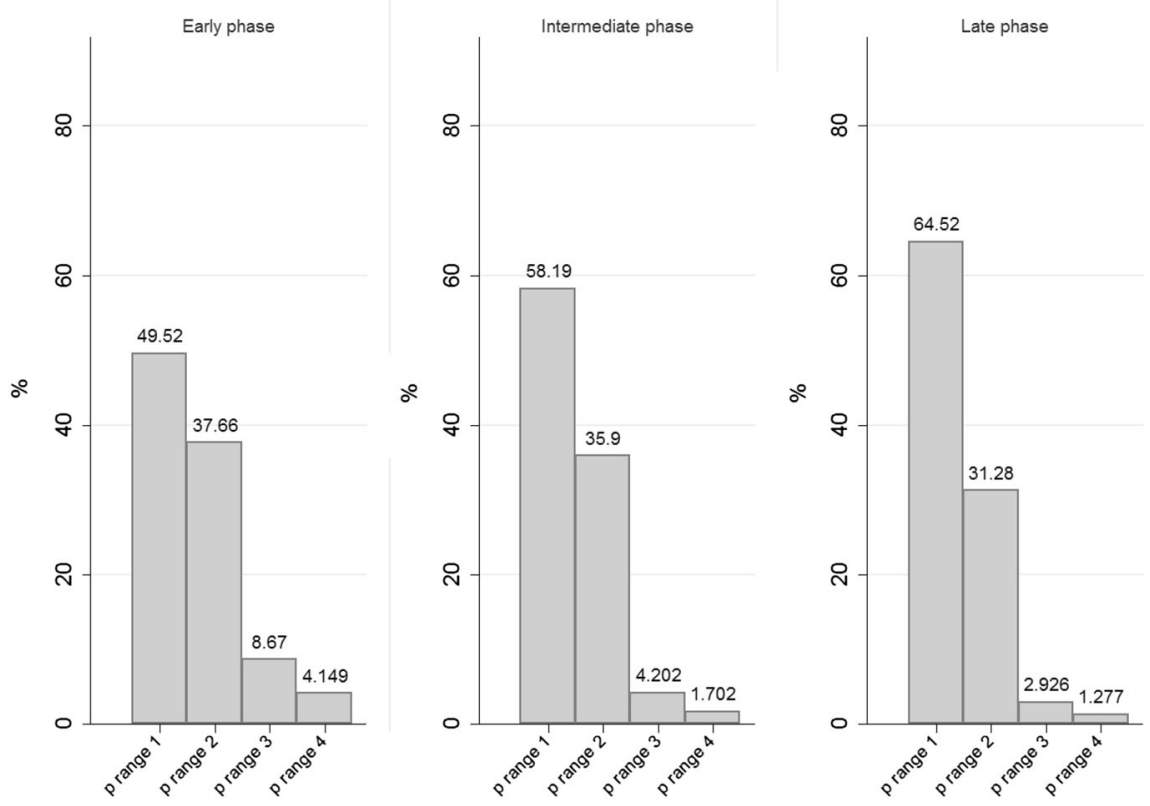

Table 3 Probability of price offers

\begin{tabular}{|c|c|c|c|c|c|c|c|c|c|c|c|c|}
\hline & \multicolumn{3}{|c|}{ Early phase $^{\mathrm{a}}$} & \multicolumn{3}{|c|}{ Intermediate phase ${ }^{a}$} & \multicolumn{3}{|c|}{ Late phase ${ }^{\mathrm{a}}$} & \multicolumn{3}{|c|}{ Two sample test of proportions ${ }^{b}$} \\
\hline & $\mathrm{F}$ & $\mathrm{M}$ & Both & $\mathrm{F}$ & M & Both & $\mathrm{F}$ & $\mathrm{M}$ & Both & $\mathrm{F}$ & M & Both \\
\hline$p \leq q \hat{v}$ & 49.47 & 49.57 & 49.52 & 58.72 & 57.66 & 58.19 & 64.89 & 64.15 & 64.52 & & & \\
\hline$p$ value & $(0.96)$ & & & $(0.64)$ & & & $(0.74)$ & & & $(0.00)$ & $(0.00)$ & $(0.00)$ \\
\hline$q \hat{v}<p<\frac{(1+q) \hat{v}}{2}$ & 36.81 & 38.51 & 37.66 & 36.06 & 35.74 & 35.9 & 30.74 & 31.81 & 31.28 & & & \\
\hline$p$ value & $(0.45)$ & & & $(0.89)$ & & & $(0.62)$ & & & $(0.01)$ & $(0.00)$ & $(0.00)$ \\
\hline$\frac{(1+q) \hat{v}}{2} \leq p<\hat{v}$ & 9.68 & 7.66 & 8.67 & 3.94 & 4.47 & 4.2 & 3.09 & 2.77 & 2.93 & & & \\
\hline$p$ value & $(0.12)$ & & & $(0.57)$ & & & $(0.68)$ & & & $(0.00)$ & $(0.00)$ & $(0.00)$ \\
\hline$p \geq \hat{v}$ & 4.04 & 4.26 & 4.15 & 1.28 & 2.13 & 1.7 & 1.28 & 1.28 & 1.28 & & & \\
\hline$p$ value & $(0.82)$ & & & $(0.15)$ & & & $(1.00)$ & & & $(0.00)$ & $(0.00)$ & $(0.00)$ \\
\hline
\end{tabular}

${ }^{a}$ Paired sample test for difference in proportions by gender within stage. $p$ values in brackets. Degrees of freedom $=1878$

b Paired sample test for difference in proportions between early and late phase for males, females and pooled observations. $p$ values in brackets. Degrees of freedom $=3758$

those who do it at least five times, there is not much consistency in sellers' attitude across phases: seller participants are either seriously restricted by ethical concerns, or not at all, or just occasionally investing in the informativeness of value messages $\hat{v}$.

Result 3 The majority of value messages overstate and increases significantly across phases only for female sellers $(p=0.01)$. There is persistent evidence of truth-telling which increases significantly $(p=0.02)$ only for male sellers. Surprisingly, understating is non-negligible but decreases across phases significantly for both, male and female sellers.

\subsection{Winner's curse}

Do buyer participants suffer from a "generalized" winner's curse which in turn offers non-optimal prices, thus earning less than predicted? Figure 6 
Table 4 Value messages: truth-telling, overstating and understating

\begin{tabular}{|c|c|c|c|c|c|c|c|c|c|c|c|c|}
\hline & \multicolumn{3}{|c|}{ Early phase $^{\mathrm{a}}$} & \multicolumn{3}{|c|}{ Intermediate phase $^{\mathrm{a}}$} & \multicolumn{3}{|c|}{ Late phase ${ }^{\mathrm{a}}$} & \multicolumn{3}{|c|}{ Two sample test of proportions } \\
\hline & $\mathrm{F}$ & M & Both & $\mathrm{F}$ & M & Both & $\mathrm{F}$ & M & Both & $\mathrm{F}$ & M & Both \\
\hline Truth-telling $(\hat{v}=v)$ & 15.95 & 15.10 & 15.53 & 14.46 & 16.70 & 15.53 & 15.95 & 19.14 & 17.55 & & & \\
\hline$p$ value & $(0.61)$ & & & $(0.18)$ & & & $(0.07)$ & & & $(1.00)$ & $(0.02)$ & $(0.10)$ \\
\hline Overstating $(\hat{v}>v)$ & 66.81 & 72.77 & 69.79 & 72.87 & 72.02 & 72.45 & 72.55 & 71.60 & 72.07 & & & \\
\hline$p$ value & $(0.00)$ & & & $(0.68)$ & & & $(0.64)$ & & & $(0.01)$ & $(0.57)$ & $(0.12)$ \\
\hline Understating $(\hat{v}<v)$ & 17.23 & 12.13 & 14.68 & 12.66 & 11.28 & 11.97 & 11.49 & 9.26 & 10.37 & & & \\
\hline$p$ value & $(0.00)$ & & & $(0.36)$ & & & $(0.11)$ & & & $(0.00)$ & $(0.04)$ & $(0.00)$ \\
\hline
\end{tabular}

${ }^{a}$ Test for difference in proportions by gender within stage. $p$ values in brackets. Degrees of freedom $=1878$

b Test for difference in proportions between early and late phase for males, females and pooled observations. $p$ values in brackets. Degrees of freedom $=3758$

reports the difference between theoretically predicted earnings and actual earnings, by level of $q$ and by experience. Figure 7 illustrates the difference between the optimal price offer and the actual price offer, by level of $q$ and of experience. ${ }^{15}$ According to Fig. 6, for $q$ lower than 0.5 and higher than 0.6 optimal earnings exceed the actual ones. Figure 7 provides an explanation: in the interval $0.1<q<0.5$ price offers which are too low often exclude trade for which the accepted optimal price $p=q$ would have implied a positive expected profit for the buyer. On the contrary, for $q>0.5$, positive price offers partly induce sellers to accept them which, however, implies negative expected profits for the buyer. Thus we confirm a winner's curse, which becomes less severe across phases, especially for extreme values of $q$.

Also the difference between the optimal and the actual price is monotonically decreasing with experience (from the early to the late phase) for all levels of $q$ : it seems that with more experience, buyers learn to avoid the winner's curse. Moreover, the effect on buyer profits is weaker since it depends on seller acceptance. In Table 14 (Appendix 1), we separate the results by gender: no gender difference emerges from this table, i.e., male and female buyers similarly suffer from the winner's curse and learn to avoid it.

\footnotetext{
$\overline{15}$ Recall that the optimal price offer is $p=q$ for $q \leq 0.5$ and $p=0$ for $q>0.5$, while expected earnings are $0.5-q$ for $q \leq 0.5$ and zero for $q>0.5$.
}

\section{Regression analysis}

The following econometric analysis tries to additionally confirm the (in)significant effects, reported above, and to explore the determinants of acceptance, suspicion and "make-up" in more detail. Exploiting the longitudinal dimension of our dataset, we estimate panel regressions with random effects to account for the fact that participants play the Acquiring-a-Company game 30 times. ${ }^{16}$ For all the regression analysis, we report standard errors clustered at individual level.

\subsection{Acceptance behavior}

Table 6 reports the results of different model specifications for the pooled sample and for the gender subsamples. Acceptance in round $t$ is a function of value of the firm $v$, parameter $q$, price offer $p$, round and acceptance decisions in the three previous rounds $(t-1, t-2$ and $t-3)$. Moreover, we alternatively include the seller payoff in the previous round $(t-1)$ or the suspicion manifested by the buyer in the

\footnotetext{
${ }^{16}$ We use the STATA command xtreg for suspicion and "make-up" and xtprobit for acceptance. As a robustness check, we also estimate a dynamic panel data model with xtabond2 which allows to fit the Arellano and Bover (1995) and Blundell and Bond (1998) estimators. The results obtained are qualitatively similar, even though xtreg and xtprobit are preferred with dataset characterized by large $\mathrm{T}$ (in our case, 30 rounds) and large $\mathrm{N}$. The estimates of the dynamic panel data model are available upon request.
} 


\section{Early Phase}
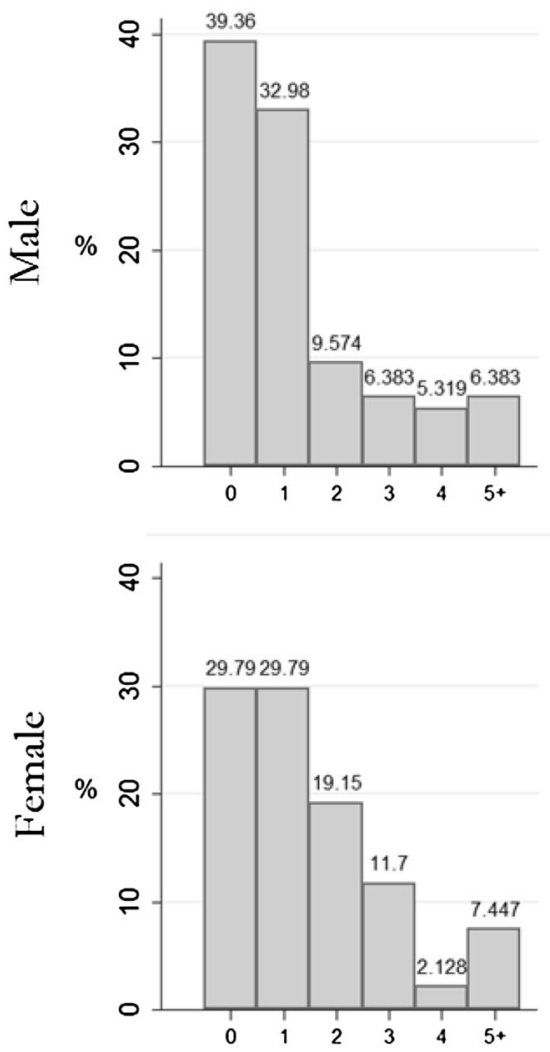

Intermediate Phase
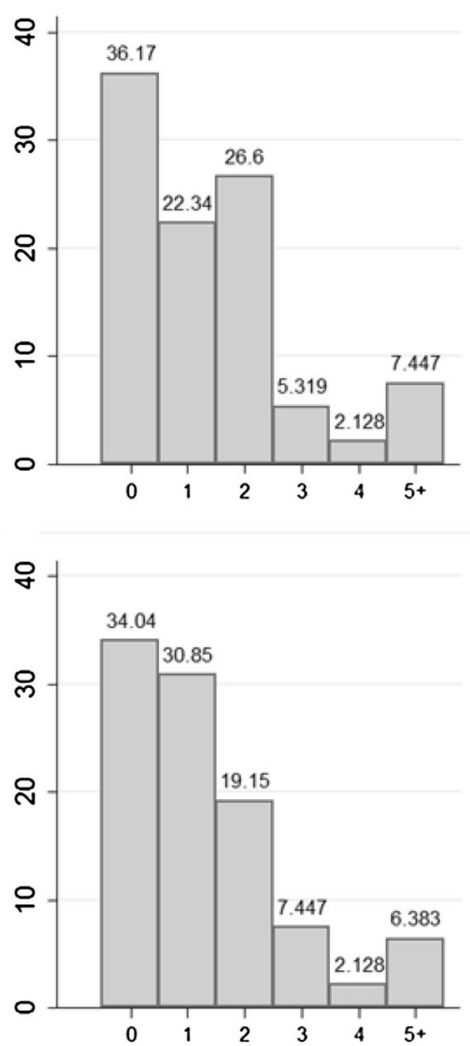

Late Phase
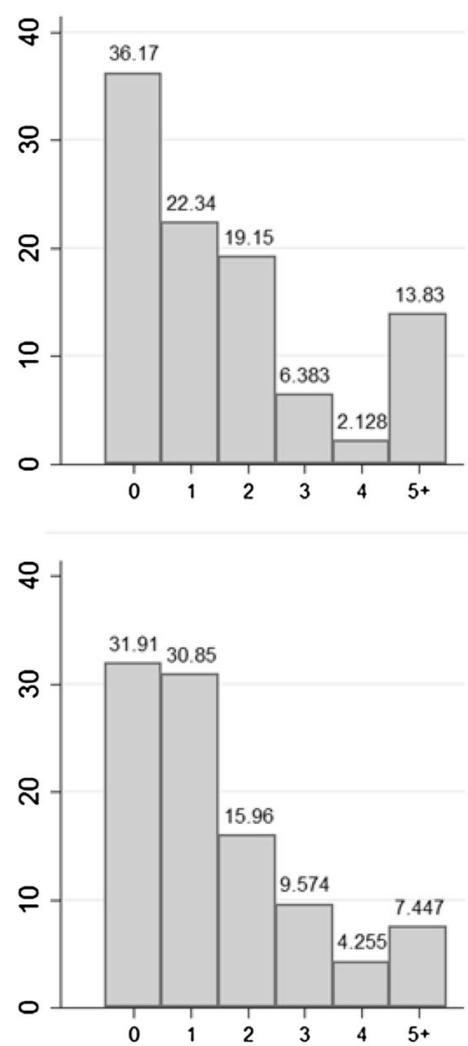

Fig. 5 Frequencies of truth-telling by phase and by gender

previous round $(t-1)$, i.e., the difference between the value message and the price offer in $t-1 .^{17}$

Columns 1 to 6 report the results for the pooled (column 1 and 2) as well as the sample separated by gender (columns 3 and 4 for female, 5 and 6 for male sellers). As expected, the value of the firm $v$ and the

\footnotetext{
17 The regression analysis in Table 6 focuses on the relation between acceptance and past experience, controlling for $q, v$ and $p$. Therefore, the analysis of path dependence is the main point of the table. Nonetheless, we were aware that price proposals may depend on seller's value message. To address this potential endogeneity, we estimated a reduced form of our model with three equations representing separately the subjects' choice sequence: first, the value message by the seller, then the price proposal by the buyer and finally the acceptance decision by the seller. This approach leads to the same qualitative results as those discussed in Table 6, and therefore it confirms that the endogeneity issue does not affect the absence of path dependence. Table 15 reported in Appendix 1 shows the estimates of the reduced form model.
}

parameter $q$ are negatively and significantly associated with the probability of acceptance, with a larger price offer enhancing acceptance. ${ }^{18}$ Interestingly, the probability of acceptance does not vary across rounds, i.e., the coefficients of the variable round are not statistically significant (with the only exception of column 1).

Looking at the results by gender the association between previous acceptance and current acceptance holds only for $t-1$ with an opposite sign for female

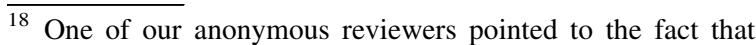
sellers via their value signals, $\hat{v}$, may have influenced the price offer and beware of such influence what might have affected their acceptance. When including additionally $\hat{v}$ as an explanatory variable in Table 6 , the effect of $\hat{v}$ is significant. In our view, the effect of $\hat{v}$ on $p$ is quite ambiguous: a seller with large $v$ signaling a large $\hat{v}$ might be annoyed by a low price offer, whereas one with low $v$ but an overstating large $\hat{v}$ should not be at all surprised.
} 
Table 5 Transition matrix of truth-telling

\begin{tabular}{|c|c|c|c|c|c|c|}
\hline \multirow[t]{2}{*}{ Times of truth-telling in phase $\mathrm{E}$ (in rows) ${ }^{\mathrm{a}}$} & \multicolumn{6}{|c|}{ Times of truth-telling in phase I (in columns) } \\
\hline & 0 & 1 & 2 & 3 & 4 & $5+$ \\
\hline $0(65)$ & $0.508^{\mathrm{b}}$ & 0.277 & 0.154 & 0.062 & 0.000 & 0.000 \\
\hline $1(59)$ & 0.322 & 0.271 & 0.339 & 0.034 & 0.017 & 0.017 \\
\hline $2(27)$ & 0.296 & 0.259 & 0.259 & 0.111 & 0.037 & 0.037 \\
\hline $3(17)$ & 0.235 & 0.353 & 0.235 & 0.059 & 0.000 & 0.118 \\
\hline $4(7)$ & 0.000 & 0.429 & 0.286 & 0.000 & 0.000 & 0.286 \\
\hline $5+(13)$ & 0.154 & 0.000 & 0.000 & 0.154 & 0.154 & 0.538 \\
\hline \multirow[t]{2}{*}{ Times of truth-telling in phase I (in rows) ${ }^{\mathrm{a}}$} & \multicolumn{6}{|c|}{ Times of truth-telling in phase L (in columns) } \\
\hline & 0 & 1 & 2 & 3 & 4 & $5+$ \\
\hline $0(66)$ & $0.500^{\mathrm{c}}$ & 0.303 & 0.121 & 0.061 & 0.000 & 0.015 \\
\hline $1(50)$ & 0.320 & 0.400 & 0.140 & 0.080 & 0.040 & 0.020 \\
\hline $2(43)$ & 0.326 & 0.163 & 0.326 & 0.093 & 0.047 & 0.047 \\
\hline $3(12)$ & 0.083 & 0.167 & 0.167 & 0.167 & 0.083 & 0.333 \\
\hline $4(4)$ & 0.000 & 0.250 & 0.250 & 0.000 & 0.000 & 0.500 \\
\hline $5+(13)$ & 0.000 & 0.000 & 0.077 & 0.077 & 0.077 & 0.769 \\
\hline
\end{tabular}

${ }^{\text {a }}$ In brackets number of sellers telling the truth $(0,1, \ldots, 5+)$ times

b For instance, $50.8 \%$ of the 65 seller participants who never told the truth in the early phase also never told the truth in the intermediate phase

${ }^{c}$ For instance, $50 \%$ of the 66 seller participants who never told the truth in the intermediate phase also never told the truth in the late phase

Fig. 6 Winner's cursedifference between predicted earnings and actual earnings

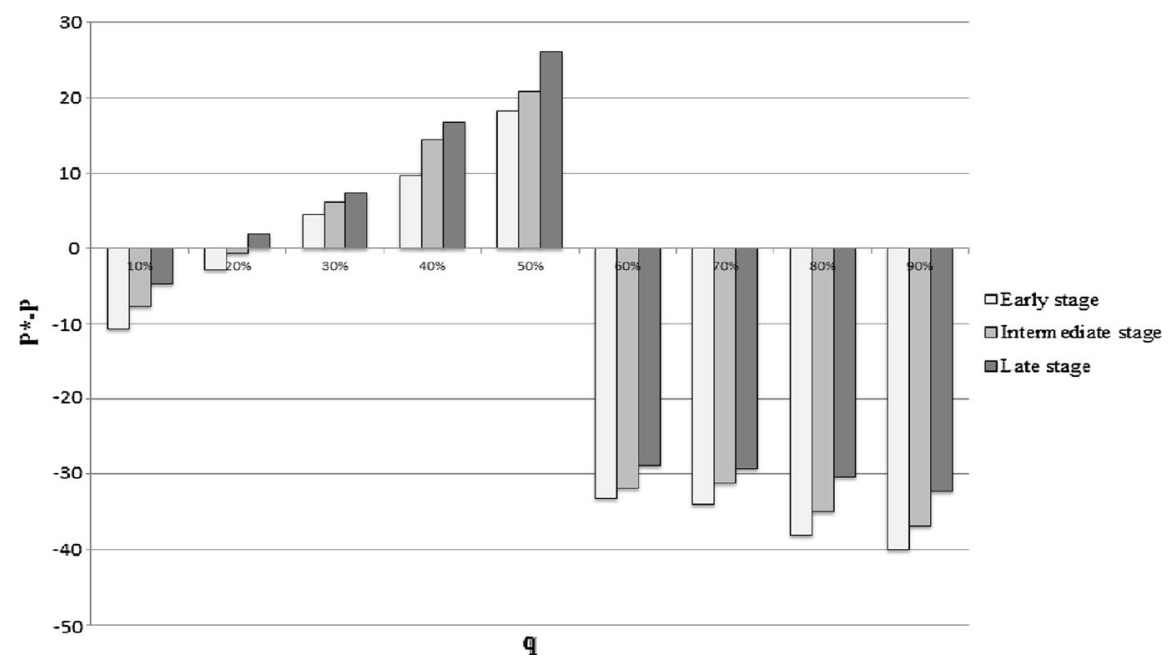

and male sellers whose significance, however, is questioned when including previous payoff, respectively previous suspicion. In particular, when we include the previous payoff, acceptance in $t-1$ positively affects acceptance in round $t$ by female sellers. On the contrary, when we include suspicion in $t-1$, acceptance in $t-1$ negatively affects acceptance in time $t$ by male sellers. It seems that male sellers are more sensitive to previous gains than females when deciding to accept or not.

In order to explore any potential gender constellation effect, we ran the same specifications, this 
Fig. 7 Winner's cursedifference between optimal price offer and actual price offer

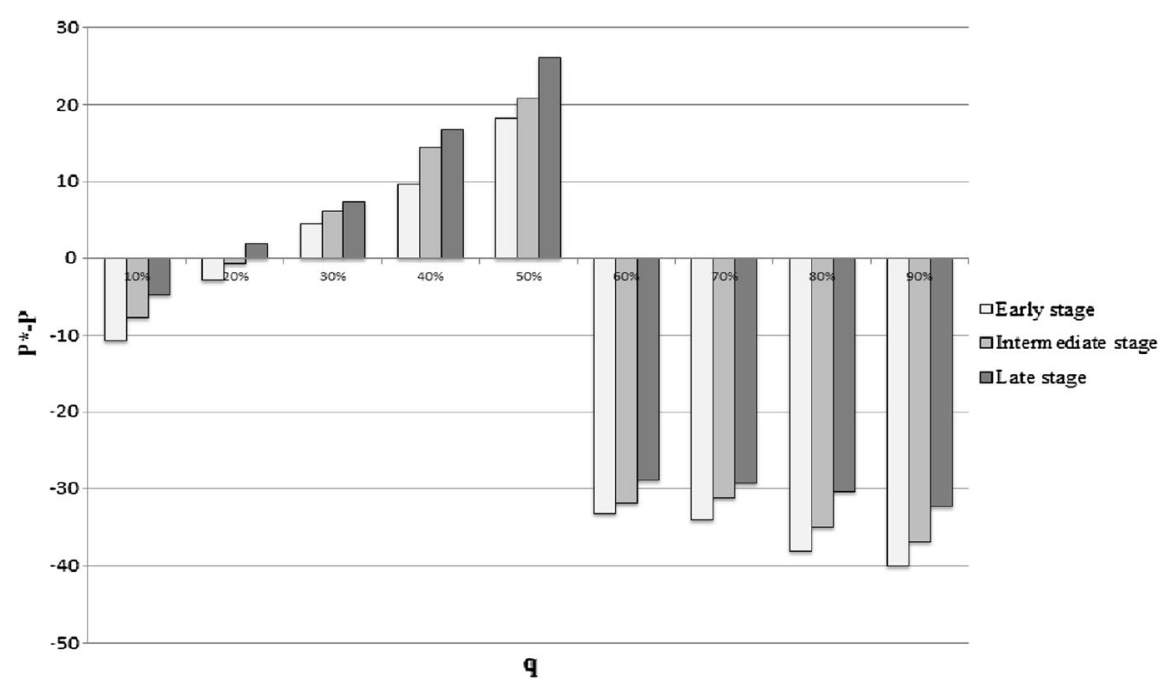

time only with data retrieved from the treatments Embedded gender constellation and Gender, separately for female and male: the coefficient of the partner's gender is positive but not statistically significant, i.e., we do not confirm a gender constellation effect.

\subsection{Suspicion}

Table 7 collects results on the dynamics of suspicion. Models 1 to 6 include data from all treatments controlling for parameter $q$, value message, round and the level of suspicion of the three lagged periods. Furthermore, we alternatively control for lagged earnings and lagged "make-up." As expected, suspicion depends positively (and significantly) on $\hat{v}$ and negatively (and significantly) on $q$. The coefficient of round is positive and significant, i.e., suspicion increases through time. The coefficient of lagged earning is negative and significant, i.e., a larger payoff in the previous round induces buyers to be less suspicious. Furthermore, larger "make-up" of sellers in the previous round significantly increases buyer suspicion.

In columns 7 to 10 , we check for gender constellation effects by considering the Embedded gender constellations treatment and the Gender treatment. Data for female (male) buyers are reported in columns 7 and 8 (9 and 10). When controlling for partner's gender, we find that the effect of lagged earning and lagged "make-up" has the same sign, but is not significant anymore. On the other hand, female buyers interacting with male sellers tend to be more suspicious. To check whether this latter result is due to a specific gender constellation effect, we run a similar specification controlling for the partner's field of study (economics vs non-economics), with data from the Other Confound treatment (see Table 8) displaying the partner's field of study as statistically not significant. ${ }^{19}$ This altogether confirms an interesting gender constellation effect: (female) participants find the information about the partner's gender relevant, and this effect is persistent across rounds.

As an additional check, we estimated the initial specification using data only from the Other Confound treatment and Unknown treatment (with no information about the trading partner), and found lagged earnings and lagged "make-up" to be even more influential and significant (see Table 9). Thus conditioning on gender (constellation) seems to interact with path dependence: male buyers are more influenced by own idiosyncratic past experiences than reacting to their partner's or own gender, whereas female buyers persistently are more suspicious when encountering male sellers.

\footnotetext{
19 "Field of study" and "Field of Study constellation" as implemented experimentally does not significantly affects making-up and acceptance.
} 


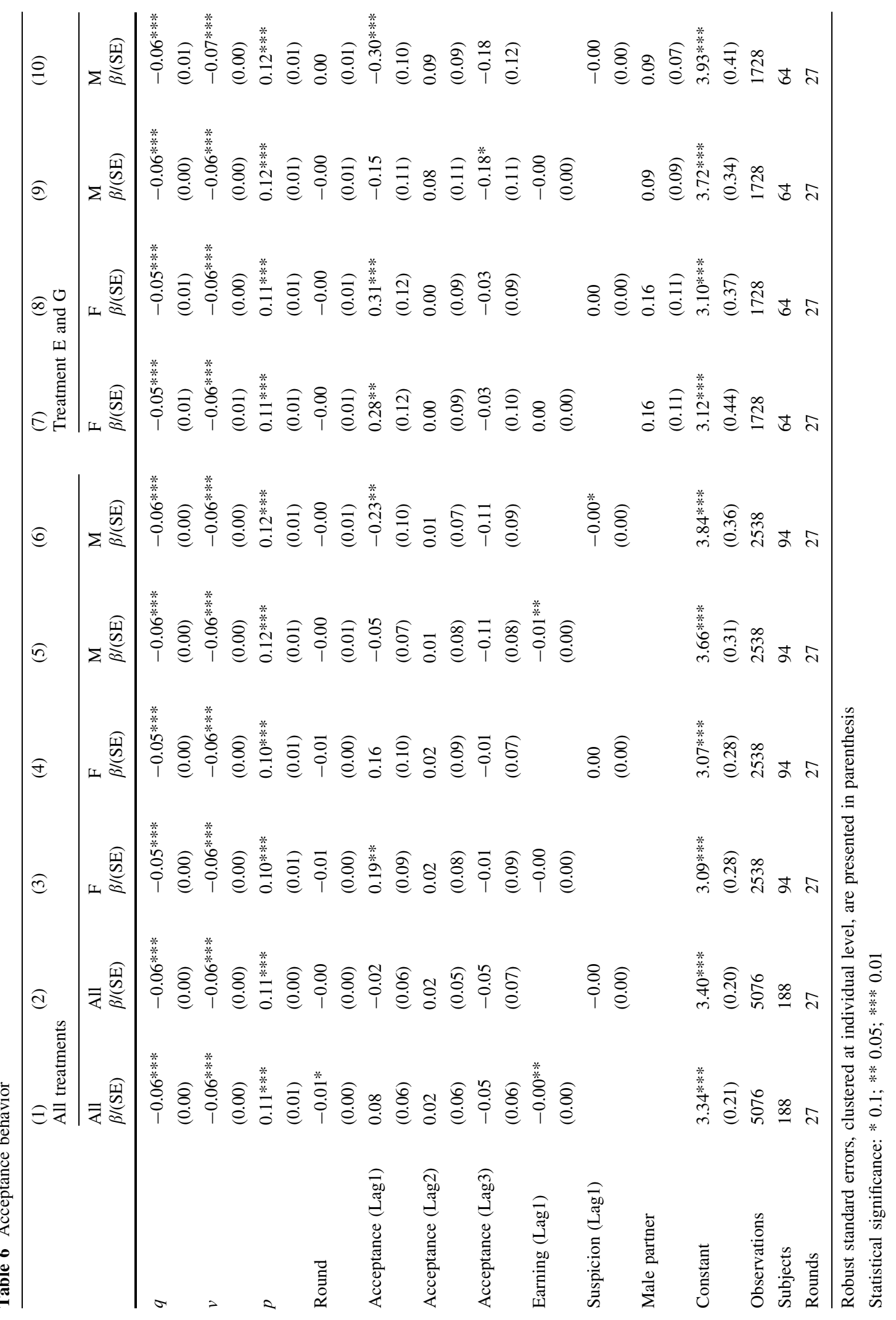




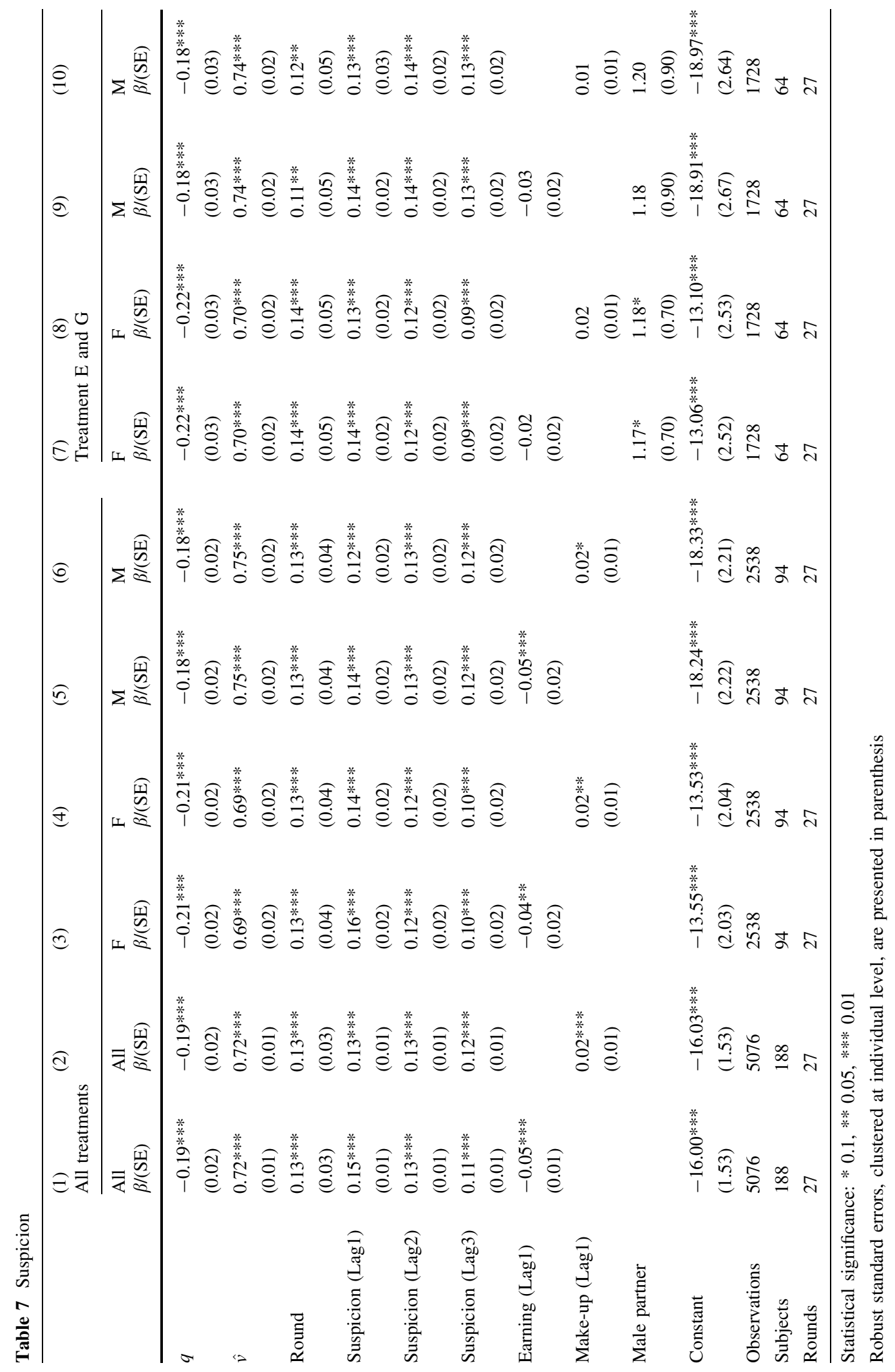


Table 8 Suspicion

\begin{tabular}{|c|c|c|c|c|}
\hline & \multicolumn{4}{|c|}{ Treatment OC } \\
\hline & $\begin{array}{l}\mathrm{F} \\
\beta /(\mathrm{SE})\end{array}$ & $\begin{array}{l}\mathrm{F} \\
\beta /(\mathrm{SE})\end{array}$ & $\begin{array}{l}\mathrm{M} \\
\beta /(\mathrm{SE})\end{array}$ & $\begin{array}{l}\mathrm{M} \\
\beta /(\mathrm{SE})\end{array}$ \\
\hline$q$ & $\begin{array}{l}-0.18 * * * \\
(0.05)\end{array}$ & $\begin{array}{l}-0.18^{* * *} \\
(0.05)\end{array}$ & $\begin{array}{l}-0.18 * * * \\
(0.06)\end{array}$ & $\begin{array}{l}-0.18 * * * \\
(0.05)\end{array}$ \\
\hline$\hat{v}$ & $\begin{array}{l}0.67 * * * \\
(0.04)\end{array}$ & $\begin{array}{l}0.67 * * * \\
(0.04)\end{array}$ & $\begin{array}{l}0.73 * * * \\
(0.04)\end{array}$ & $\begin{array}{l}0.73 * * * \\
(0.04)\end{array}$ \\
\hline Round & $\begin{array}{l}0.14 \\
(0.11)\end{array}$ & $\begin{array}{l}0.15 \\
(0.11)\end{array}$ & $\begin{array}{l}0.11 \\
(0.08)\end{array}$ & $\begin{array}{l}0.11 \\
(0.09)\end{array}$ \\
\hline Suspicion (Lag1) & $\begin{array}{l}0.14 * * * \\
(0.04)\end{array}$ & $\begin{array}{l}0.12 * * \\
(0.05)\end{array}$ & $\begin{array}{l}0.13 * * \\
(0.05)\end{array}$ & $\begin{array}{l}0.09 * \\
(0.05)\end{array}$ \\
\hline Suspicion (Lag2) & $\begin{array}{l}0.12 * * * \\
(0.03)\end{array}$ & $\begin{array}{l}0.13 * * * \\
(0.03)\end{array}$ & $\begin{array}{l}0.07 * * \\
(0.04)\end{array}$ & $\begin{array}{l}0.08 * * \\
(0.04)\end{array}$ \\
\hline Suspicion (Lag3) & $\begin{array}{l}0.10 * * \\
(0.04)\end{array}$ & $\begin{array}{l}0.10 * * \\
(0.04)\end{array}$ & $\begin{array}{l}0.14 * * * \\
(0.05)\end{array}$ & $\begin{array}{l}0.13 * * * \\
(0.05)\end{array}$ \\
\hline Earning (Lag1) & $\begin{array}{l}-0.06^{*} \\
(0.04)\end{array}$ & & $\begin{array}{l}-0.13^{* *} \\
(0.05)\end{array}$ & \\
\hline Make-up (Lag1) & & $\begin{array}{l}0.03 \\
(0.03)\end{array}$ & & $\begin{array}{l}0.07 * * \\
(0.04)\end{array}$ \\
\hline Partner study: economics $=1$ & $\begin{array}{l}2.92 \\
(2.00)\end{array}$ & $\begin{array}{l}3.10 \\
(2.08)\end{array}$ & $\begin{array}{l}0.65 \\
(1.80)\end{array}$ & $\begin{array}{l}0.75 \\
(1.68)\end{array}$ \\
\hline Constant & $\begin{array}{l}-14.16^{* * * *} \\
(5.33)\end{array}$ & $\begin{array}{l}-14.46^{* * * *} \\
(5.30)\end{array}$ & $\begin{array}{l}-15.63 * * \\
(6.44)\end{array}$ & $\begin{array}{l}-15.90 * * \\
(6.50)\end{array}$ \\
\hline Observations & 432 & 432 & 432 & 432 \\
\hline Subjects & 16 & 16 & 16 & 16 \\
\hline Rounds & 27 & 27 & 27 & 27 \\
\hline
\end{tabular}

Robust standard errors, clustered at individual level, are presented in parenthesis Statistical significance: * $0.1 ; * * 0.05 ; * * * 0.01$

\subsection{Make-up}

Table 10 collects results on the dynamics of "makeup." Models 1 to 6 include data from all treatments controlling for parameter $q$, value of the firm, round and lagged level of "make-up" with up to three periods. Furthermore, we alternatively control for lagged earnings and lagged suspicion. As expected, the coefficients of $q$ and $v$ are, respectively, positive and negative, and highly significant. The round is never statistically significant, i.e., "make-up" does not follow a clear path across rounds. However, there is persistence in cheating: the influence of lagged "make-up" is positive and significant. Lagged suspicion is always positive and significant: sellers increase "make-up" after having met a suspicious buyer. Interestingly, the coefficient of the payoff in the previous round is positive and significant for male sellers but negative for female sellers. To explore any potential gender constellation effect for acceptance and suspicion, we run the same specifications only with data from the treatments Embedded gender constellations and Gender, separately for female and male sellers without diagnosing any significant effect, i.e., the coefficient of the partner's gender is not statistically significant. ${ }^{20}$

\section{Conclusions}

This study is a rather systematic attempt to account for possible effects of gender (constellation) in an easily understood (by participants) but nonetheless complex

\footnotetext{
${ }^{20}$ Using data from the Treatment Other Confound, we also investigate potential effects of including the partner's field of study. We find that this variable does not have any effect with all our results being confirmed.
} 
Table 9 Suspicion

\begin{tabular}{|c|c|c|}
\hline & \multicolumn{2}{|c|}{ Treatment U \& OC } \\
\hline & $\begin{array}{l}\text { All } \\
\beta /(\mathrm{SE})\end{array}$ & $\begin{array}{l}\text { All } \\
\beta /(\mathrm{SE})\end{array}$ \\
\hline$q$ & $\begin{array}{l}-0.18^{* * *} \\
(0.03)\end{array}$ & $\begin{array}{l}-0.18^{* * *} \\
(0.03)\end{array}$ \\
\hline$\hat{v}$ & $\begin{array}{l}0.71 * * * \\
(0.02)\end{array}$ & $\begin{array}{l}0.71 * * * \\
(0.02)\end{array}$ \\
\hline Round & $\begin{array}{l}0.14 * * * \\
(0.05)\end{array}$ & $\begin{array}{l}0.14 * * * \\
(0.05)\end{array}$ \\
\hline Suspicion (Lag1) & $\begin{array}{l}0.16 * * * \\
(0.02)\end{array}$ & $\begin{array}{l}0.13 * * * \\
(0.02)\end{array}$ \\
\hline Suspicion (Lag2) & $\begin{array}{l}0.12 * * * \\
(0.02)\end{array}$ & $\begin{array}{l}0.12 * * * \\
(0.02)\end{array}$ \\
\hline Suspicion (Lag3) & $\begin{array}{l}0.11 * * * \\
(0.02)\end{array}$ & $\begin{array}{l}0.12 * * * \\
(0.02)\end{array}$ \\
\hline Earning (Lag1) & $\begin{array}{l}-0.10^{* * *} \\
(0.02)\end{array}$ & \\
\hline Make-up (Lag1) & & $\begin{array}{l}0.04 * * \\
(0.02)\end{array}$ \\
\hline Constant & $\begin{array}{l}-16.43^{* * * *} \\
(2.69)\end{array}$ & $\begin{array}{l}-16.56^{* * *} \\
(2.69)\end{array}$ \\
\hline Observations & 1620 & 1620 \\
\hline Subjects & 60 & 60 \\
\hline Rounds & 27 & 27 \\
\hline
\end{tabular}

Robust standard errors, clustered at individual level, are presented in parenthesis

Statistical significance: $* 0.1 ; * * 0.05 ; * * * 0.01$

environment allowing for asymmetric information, truth-telling and deception, other regarding concerns in bargaining and conditioning on gender (constellation) as well as on another confound (field of study). Our experimental workhorse is the modified Acquiring-a-Company game (Samuelson and Bazerman 1985), which allows the better informed seller to send a value message before the buyer's price offer. The main motivation here has been to explore how both, experience and gender (constellation), influence behavior of buyers and sellers. Rather than speculating about gender differences in individual learning, for which there exists no obvious hypotheses, we wanted to see which gender (constellation) and other behavioral effects survive extensive game playing experience and whether conditioning on gender constellation can evolve anew. We did not experimentally induce initial female handicap, e.g., by a lower parameter $q$ of female than of male sellers. Such an initial handicap strongly has been prevailing in the field due to traditional labor division in most human societies.

Our findings demonstrate how conditioning on gender (constellation) is affected by game playing experience and past outcome and behavior. Furthermore, the main experience and gender (constellation) effects apply to suspicion, i.e., the pricing behavior in light of the received values messages. Interestingly, sellers adapt more to past experiences, differing from buyers, who condition more on gender constellation.

Compared to our companion paper based on playing a single incentivized round of the Modified Acquiring-a-Company game, in recursive play by (random) strangers gender differences emerge across phases. Male and female participants learn to react differently both to past behavior and to the gender of their trading partner.

Additionally, there are other surprising results: the significantly positive share of underreporting and the persistence of truth-telling messages whose reasons are "obsessive truth-telling" or "investing in the informativeness of value messages." And, more fundamentally, there is hardly any evidence of other regarding concerns suggesting that these are rather context dependent and likely to be crowed out in stochastic environments, especially those involving asymmetric information.

Our experimental workhorse allows for chance effects (the random value $v$ ), asymmetric information about $v$, bargaining whether to trade and, if so, how to share the gains from welfare enhancing trade, with buyer participants at risk of suffering from a winner's curse, and-due to our modification-also from deception (see Gneezy et al. 2013, for some experimental studies). According to us, such a stylized complex decision environment can sooner or later crowd out or at least discourage attempts to condition decision making on gender (constellation), which may not prove when the cognitive load is less demanding. In any future research, this could be tested by exploring experience and gender effects for simpler versions of our setup, e.g., by forcing seller participants to accept whatever price proposal, or by making deception costly.

From a theoretical perspective, it is shown-as predicted-that even extensive game playing 


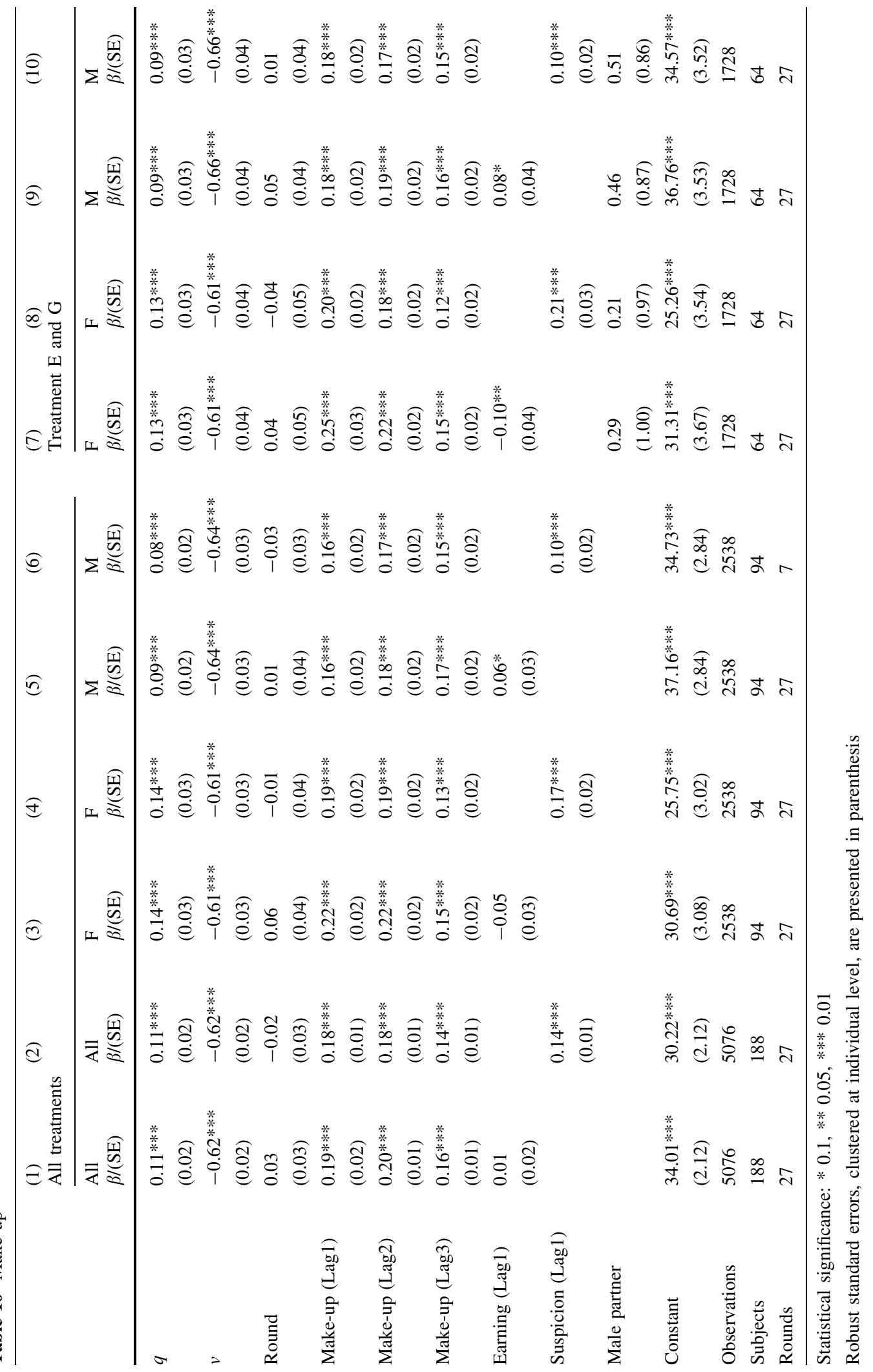


experience does not imply convergence to equilibrium play, e.g., to price offers $p=q$ for $q \leq 0.5$ and $p=0$ for $q>0.5$. Nevertheless, behavior is improved by experience: the winner's curse is more frequently avoided, with seller participants more frequently rejecting unprofitable price offers which, of course, excludes trade (although it is welfare enhancing).

From a theoretical perspective, it also might be interesting on how the recursive play of the Modified Acquiring-a-Company game would evolve if participants are constantly paired up with the same participant in the other role. Would seller participants initially signal the truth and switch to "making-up" only when approaching the last round? Would buyer participants initially believe in the truth of $\hat{v}$ and suggest prices which share $(1-q) \hat{v}$ equally? These are interesting research questions indeed. However, in our view, such a scenario does not seem very realistic: when successively bargaining over takeovers this will hardly ever be done by the same parties.

\section{Appendix 1: Tables}

See Tables 11, 12, 13, 14 and 15 and Fig. 8.

Table 11 Time (s) for acceptance by $p, q$, experience and gender

\begin{tabular}{|c|c|c|c|c|c|c|c|c|c|c|c|c|c|c|c|}
\hline & \multicolumn{3}{|c|}{ Early stage } & \multicolumn{3}{|c|}{ Intermediate stage } & \multicolumn{3}{|c|}{ Late stage } & \multicolumn{3}{|c|}{ All rounds } & \multicolumn{3}{|c|}{$\mathrm{T}$ tests: early-late } \\
\hline & $\mathrm{F}$ & M & Both & $\mathrm{F}$ & M & Both & $\mathrm{F}$ & M & Both & $\mathrm{F}$ & M & Both & $\mathrm{F}$ & M & Both \\
\hline$p \leq q v$ & $\begin{array}{l}6.40 \\
(0.63)\end{array}$ & 6.20 & 6.30 & $\begin{array}{l}3.60 \\
(0.47)\end{array}$ & 3.41 & 3.50 & $\begin{array}{l}2.63 \\
(0.07)\end{array}$ & 3.13 & 2.88 & $\begin{array}{l}4.08 \\
(0.74)\end{array}$ & 4.14 & 4.11 & $(0.00)$ & $(0.00)$ & $(0.00)$ \\
\hline$v>p>q v$ & $\begin{array}{l}7.34 \\
(0.27)\end{array}$ & 6.85 & 7.10 & $\begin{array}{l}5.00 \\
(0.38)\end{array}$ & 4.66 & 4.83 & $\begin{array}{l}3.75 \\
(0.44)\end{array}$ & 3.47 & 3.60 & $\begin{array}{l}5.44 \\
(0.08)\end{array}$ & 5.01 & 5.22 & $(0.00)$ & $(0.00)$ & $(0.00)$ \\
\hline$p \geq v$ & $\begin{array}{l}6.68 \\
(0.16)\end{array}$ & 5.82 & 6.23 & $\begin{array}{l}3.94 \\
(0.54)\end{array}$ & 4.18 & 4.05 & $\begin{array}{l}3.19 \\
(0.09)\end{array}$ & 2.54 & 2.87 & $\begin{array}{l}4.76 \\
(0.23)\end{array}$ & 4.40 & 4.58 & $(0.00)$ & $(0.00)$ & $(0.00)$ \\
\hline \multicolumn{16}{|c|}{ By level of $q: q \leq 50$} \\
\hline$p \leq q v$ & $\begin{array}{l}6.14 \\
(0.92)\end{array}$ & 6.20 & 6.16 & $\begin{array}{l}3.88 \\
(0.14)\end{array}$ & 3.18 & 3.53 & $\begin{array}{l}2.56 \\
(0.15)\end{array}$ & 3.18 & 2.86 & $\begin{array}{l}4.09 \\
(0.94)\end{array}$ & 4.06 & 4.07 & $(0.00)$ & $(0.00)$ & $(0.00)$ \\
\hline$v>p>q v$ & $\begin{array}{l}7.45 \\
(0.39)\end{array}$ & 7.02 & 7.24 & $\begin{array}{l}4.74 \\
(0.76)\end{array}$ & 4.62 & 4.68 & $\begin{array}{l}3.86 \\
(0.41)\end{array}$ & 3.53 & 3.69 & $\begin{array}{l}5.40 \\
(0.24)\end{array}$ & 5.08 & 5.24 & $(0.00)$ & $(0.00)$ & $(0.00)$ \\
\hline$p \geq v$ & $\begin{array}{l}7.19 \\
(0.09)\end{array}$ & 5.41 & 6.27 & $\begin{array}{l}3.10 \\
(0.11)\end{array}$ & 3.96 & 3.53 & $\begin{array}{l}2.39 \\
(0.53)\end{array}$ & 2.14 & 2.26 & $\begin{array}{l}4.57 \\
(0.32)\end{array}$ & 4.07 & 4.32 & $(0.00)$ & $(0.00)$ & $(0.00)$ \\
\hline \multicolumn{16}{|c|}{ By level of $q: q>50$} \\
\hline$p \leq q v$ & $\begin{array}{l}6.60 \\
(0.48)\end{array}$ & 6.20 & 6.40 & $\begin{array}{l}3.43 \\
(0.72)\end{array}$ & 3.54 & 3.49 & $\begin{array}{l}2.68 \\
(0.24)\end{array}$ & 3.09 & 2.88 & $\begin{array}{l}4.07 \\
(0.63)\end{array}$ & 4.19 & 4.13 & $(0.00)$ & $(0.00)$ & $(0.00)$ \\
\hline$v>p>q v$ & $\begin{array}{l}6.86 \\
(0.35)\end{array}$ & 5.92 & 6.44 & $\begin{array}{l}6.20 \\
(0.26)\end{array}$ & 4.89 & 5.54 & $\begin{array}{l}3.09 \\
(0.86)\end{array}$ & 3.21 & 3.16 & $\begin{array}{l}5.63 \\
(0.09)\end{array}$ & 4.64 & 5.13 & $(0.00)$ & $(0.00)$ & $(0.00)$ \\
\hline$p \geq v$ & $\begin{array}{l}6.20 \\
(0.99)\end{array}$ & 6.21 & 6.21 & $\begin{array}{l}4.52 \\
(0.77)\end{array}$ & 4.36 & 4.44 & $\begin{array}{l}3.81 \\
(0.12)\end{array}$ & 2.89 & 3.38 & $\begin{array}{l}4.92 \\
(0.54)\end{array}$ & 4.69 & 4.81 & $(0.00)$ & $(0.00)$ & $(0.00)$ \\
\hline
\end{tabular}

$p$ values in parenthesis: we run tests both for static gender differences (above each observation) and dynamic differences across periods for male, female and pooled sample (last three columns on the right) 


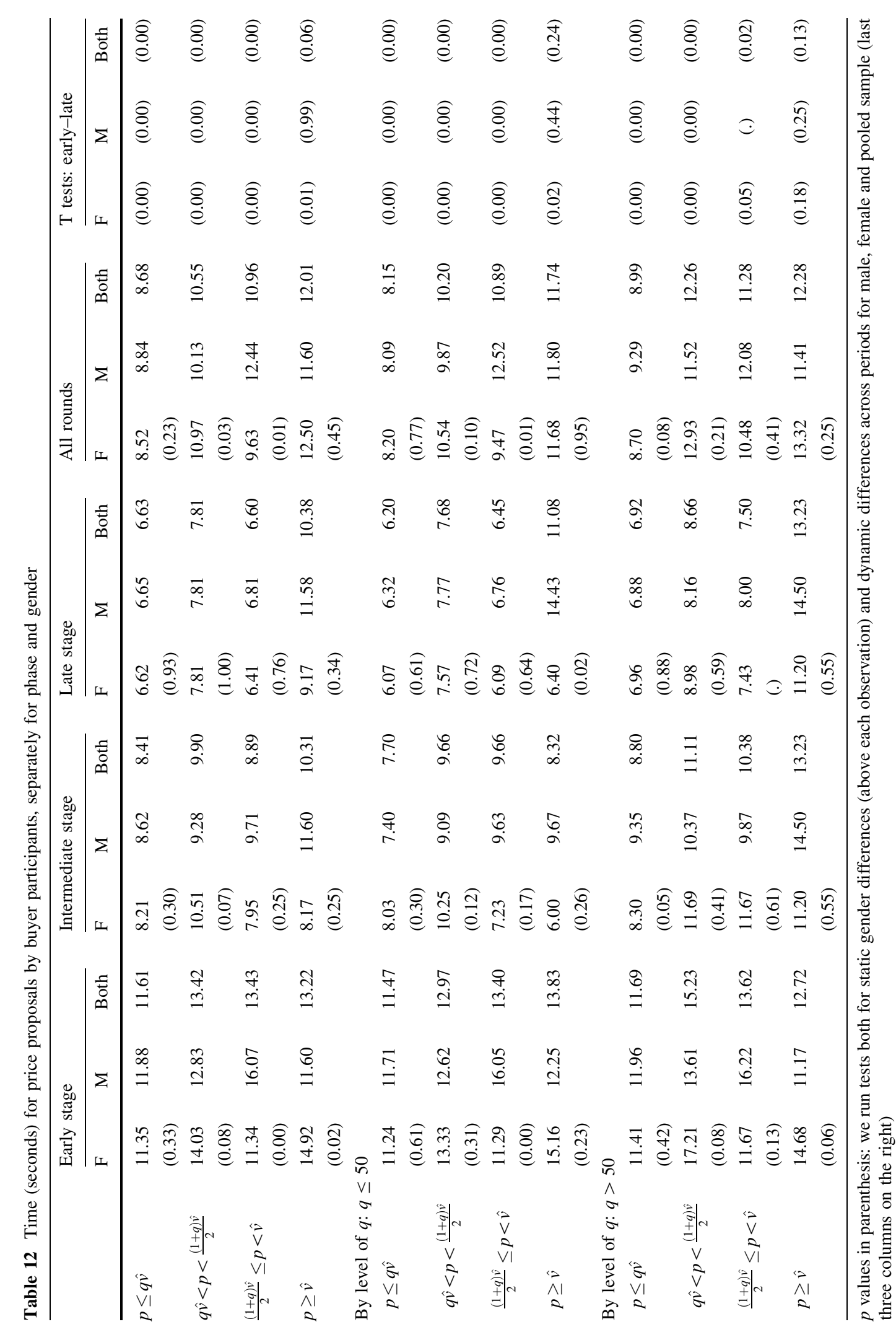


Table 13 Time for message by truth-telling, overstating and understating

\begin{tabular}{|c|c|c|c|c|c|c|c|c|c|c|c|c|c|c|c|}
\hline & \multicolumn{3}{|c|}{ Early stage } & \multicolumn{3}{|c|}{ Intermediate stage } & \multicolumn{3}{|c|}{ Late stage } & \multicolumn{3}{|c|}{ All rounds } & \multicolumn{3}{|c|}{$\mathrm{T}$ tests: early-late } \\
\hline & $\mathrm{F}$ & M & Both & $\mathrm{F}$ & M & Both & $\mathrm{F}$ & M & Both & $\mathrm{F}$ & M & Both & $\mathrm{F}$ & M & Both \\
\hline$v=\hat{v}$ & $\begin{array}{l}10.47 \\
(0.46)\end{array}$ & 10.98 & 10.72 & $\begin{array}{l}6.94 \\
(0.57)\end{array}$ & 7.19 & 7.08 & $\begin{array}{l}5.33 \\
(0.25)\end{array}$ & 5.67 & 5.52 & $\begin{array}{l}7.60 \\
(0.65)\end{array}$ & 7.74 & 7.68 & $(0.00)$ & $(0.00)$ & $(0.00)$ \\
\hline $\begin{array}{l}\text { Overstating value } \\
\text { of } v\end{array}$ & $\begin{array}{l}11.18 \\
(0.17)\end{array}$ & 11.60 & 11.40 & $\begin{array}{l}7.75 \\
(0.45)\end{array}$ & 7.93 & 7.84 & $\begin{array}{l}6.19 \\
(0.60)\end{array}$ & 6.30 & 6.24 & $\begin{array}{l}8.30 \\
(0.04)\end{array}$ & 8.62 & 8.46 & $(0.00)$ & $(0.00)$ & $(0.00)$ \\
\hline $\begin{array}{l}\text { Understating } \\
\text { value of } v\end{array}$ & $\begin{array}{l}13.31 \\
(0.43)\end{array}$ & 12.67 & 13.05 & $\begin{array}{l}8.38 \\
(0.63)\end{array}$ & 8.68 & 8.52 & $\begin{array}{l}6.38 \\
(0.63)\end{array}$ & 6.63 & 6.49 & $\begin{array}{l}9.88 \\
(0.51)\end{array}$ & 9.58 & 9.75 & $(0.00)$ & $(0.00)$ & $(0.00)$ \\
\hline \multicolumn{16}{|c|}{ By level of $q$ : $q \leq 0.5$} \\
\hline$v=\hat{v}$ & $\begin{array}{l}9.70 \\
(0.17)\end{array}$ & 10.86 & 10.27 & $\begin{array}{l}6.58 \\
(0.37)\end{array}$ & 7.10 & 6.86 & $\begin{array}{l}5.27 \\
(0.13)\end{array}$ & 5.88 & 5.59 & $\begin{array}{l}7.19 \\
(0.12)\end{array}$ & 7.81 & 7.51 & $(0.00)$ & $(0.00)$ & $(0.00)$ \\
\hline $\begin{array}{l}\text { Overstating } \\
\text { value of } v\end{array}$ & $\begin{array}{l}11.21 \\
(0.41)\end{array}$ & 11.56 & 11.39 & $\begin{array}{l}7.45 \\
(0.30)\end{array}$ & 7.79 & 7.62 & $\begin{array}{l}6.07 \\
(0.26)\end{array}$ & 6.38 & 6.22 & $\begin{array}{l}8.19 \\
(0.05)\end{array}$ & 8.63 & 8.41 & $(0.00)$ & $(0.00)$ & $(0.00)$ \\
\hline $\begin{array}{l}\text { Understating } \\
\text { value of } v\end{array}$ & $\begin{array}{l}13.16 \\
(0.73)\end{array}$ & 12.80 & 13.02 & $\begin{array}{l}8.89 \\
(0.40)\end{array}$ & 8.26 & 8.60 & $\begin{array}{l}5.95 \\
(0.25)\end{array}$ & 6.55 & 6.23 & $\begin{array}{l}9.86 \\
(0.34)\end{array}$ & 9.31 & 9.62 & $(0.00)$ & $(0.00)$ & $(0.00)$ \\
\hline \multicolumn{16}{|c|}{ By level of $q: q>0.5$} \\
\hline$v=\hat{v}$ & $\begin{array}{l}11.52 \\
(0.76)\end{array}$ & 11.16 & 11.35 & $\begin{array}{l}7.40 \\
(0.88)\end{array}$ & 7.30 & 7.35 & $\begin{array}{l}5.43 \\
(0.95)\end{array}$ & 5.41 & 5.42 & $\begin{array}{l}8.17 \\
(0.32)\end{array}$ & 7.66 & 7.90 & $(0.00)$ & $(0.00)$ & $(0.00)$ \\
\hline $\begin{array}{l}\text { Overstating } \\
\text { value of } v\end{array}$ & $\begin{array}{l}11.14 \\
(0.24)\end{array}$ & 11.64 & 11.40 & $\begin{array}{l}8.05 \\
(0.90)\end{array}$ & 8.10 & 8.07 & $\begin{array}{l}6.33 \\
(0.67)\end{array}$ & 6.20 & 6.26 & $\begin{array}{l}8.41 \\
(0.36)\end{array}$ & 8.62 & 8.51 & $(0.00)$ & $(0.00)$ & $(0.00)$ \\
\hline $\begin{array}{c}\text { Understating } \\
\text { value of } v\end{array}$ & $\begin{array}{l}13.65 \\
(0.31)\end{array}$ & 12.43 & 13.11 & $\begin{array}{l}7.09 \\
(0.02)\end{array}$ & 9.66 & 8.33 & $\begin{array}{l}7.29 \\
(0.74)\end{array}$ & 6.86 & 7.12 & $\begin{array}{l}9.93 \\
(0.75)\end{array}$ & 10.18 & 10.04 & $(0.00)$ & $(0.00)$ & $(0.00)$ \\
\hline
\end{tabular}

$p$ values in parenthesis: we run tests both for static gender differences (above each observation) and dynamic differences across periods for male, female and pooled sample (last three columns on the right)

Table 14 Winner's curse, measured by differences in earnings and prices

\begin{tabular}{lccccccccc}
\hline$q$ levels & $10 \%$ & $20 \%$ & $30 \%$ & $40 \%$ & $50 \%$ & $60 \%$ & $70 \%$ & $80 \%$ & $90 \%$ \\
\hline Difference between optimal earning and actual earning & & & & & & \\
All rounds & 22.06 & 15.10 & 10.25 & 5.10 & -2.11 & 0.26 & 3.60 & 4.91 & 6.23 \\
Early stage & 24.97 & 16.35 & 11.11 & 4.60 & -1.39 & 0.26 & 3.34 & 7.05 & 6.65 \\
Intermediate stage & 21.44 & 13.19 & 9.68 & 3.52 & -3.11 & -0.35 & 3.84 & 4.06 & 7.14 \\
Late stage & 19.77 & 15.91 & 9.90 & 7.00 & -1.98 & 0.90 & 3.63 & 3.79 & 4.89 \\
$t$ test E versus L $(p$ value) & $(0.05)$ & $(0.86)$ & $(0.52)$ & $(0.21)$ & $(0.70)$ & $(0.64)$ & $(0.81)$ & $(0.01)$ & $(0.17)$ \\
Difference between optimal & price and actual price & & & & & -31.49 & -34.42 & -36.28 \\
All rounds & -7.64 & -0.63 & 6.05 & 13.83 & 21.60 & -31.33 & -31.49 \\
Early stage & -10.63 & -2.77 & 4.59 & 9.68 & 18.27 & -33.16 & -33.99 & -38.10 & -39.94 \\
Intermediate stage & -7.64 & -0.62 & 6.19 & 14.37 & 20.78 & -31.89 & -31.21 & -35.01 & -36.80 \\
Late stage & -4.71 & 1.90 & 7.41 & 16.77 & 26.09 & -28.92 & -29.23 & -30.31 & -32.31 \\
$t$ test E versus L $(p$ value) & $(0.00)$ & $(0.00)$ & $(0.03)$ & $(0.00)$ & $(0.00)$ & $(0.01)$ & $(0.00)$ & $(0.00)$ & $(0.00)$ \\
\hline
\end{tabular}

$p$ values in parenthesis: we run tests for dynamic differences across periods 


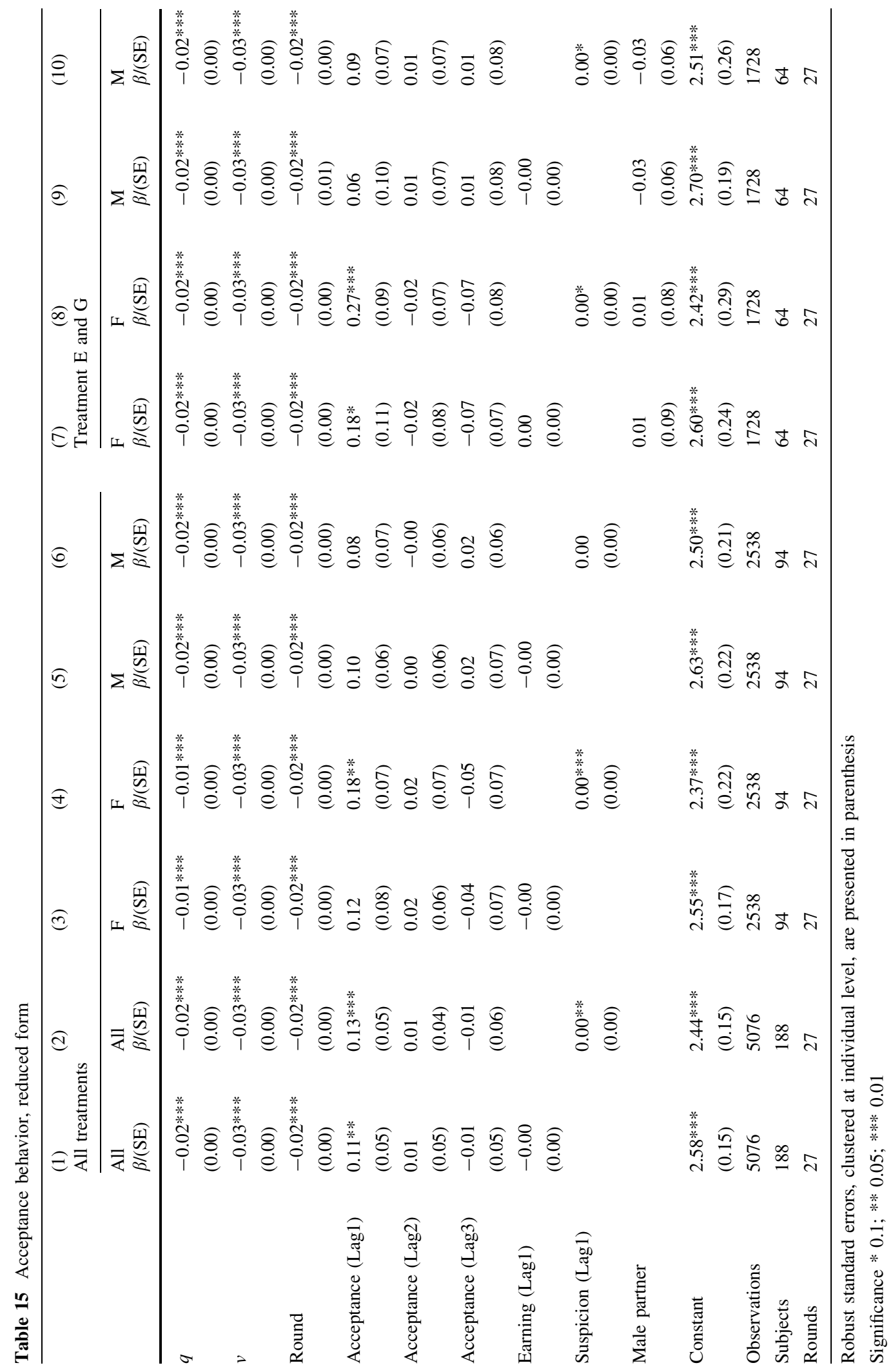




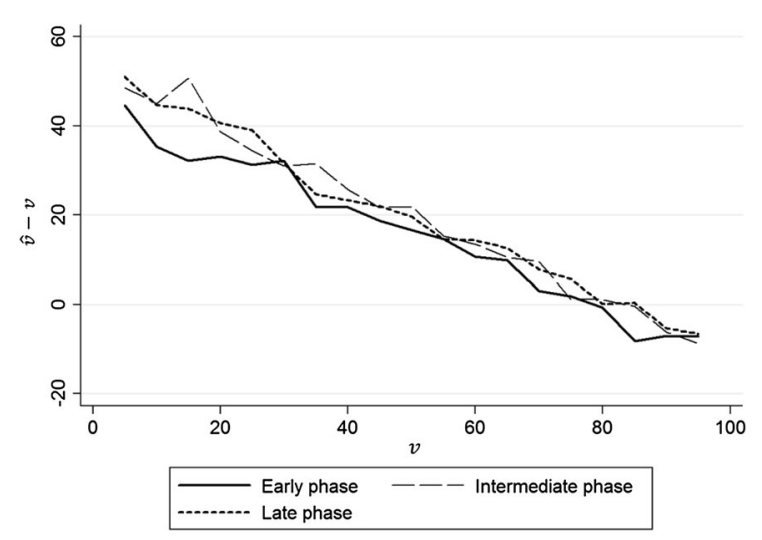

Fig. 8 Value message and the true value by phase

\section{Appendix 2: Instructions}

Introduction

Welcome to our experiment!

During this experiment, you will be asked to make several decisions and so will the other participants.

Please read the instructions carefully. Your decisions, as well as the decisions of the other participants, will determine your earnings according to some rules, which will be shortly explained later. In addition to your earnings from your decisions over the course of the experiment, you will receive a participation fee of 10 euro. Besides this amount, you can earn more euro. However, there is also a possibility of losing part of the participation fee, as it will be explained in the next section of these instructions. But do not worry: you will never be asked to pay with your own money, as your losses during the tasks will be covered by the participation fee. The participation fee and any additional amount of money you will earn during the experiment will be paid individually immediately at the end of the experiment; no other participant will know how much you earned. All monetary amounts in the experiment will be computed in ECU (Experimental Currency Units). At the end of the experiment, all earned in ECUs will be converted into euro using the following exchange rate:

\section{$30 \mathrm{ECU}=1$ euro}

You will be making your decisions by clicking on appropriate buttons on the screen. All the participants are reading the same instructions and taking part in this experiment for the first time, as you are.
Please note that hereafter any form of communication between the participants is strictly prohibited. If you violate this rule, you will be excluded from the experiment with no payment. If you have any questions, please raise your hand. The experimenter will come to you and answer your questions individually.

\section{Description of the experiment}

This experiment is fully computerized. This experiment consists of the following four phases, each composed by a different number of rounds: Phase I of 1 round, Phase II of 30 rounds, Phase III of 12 rounds, and Phase IV of 10 rounds. After completing Phase I, you will proceed to Phase II; after completing Phase II, you will proceed to Phase III; after completing Phase III you will proceed to Phase IV. You can earn money in each phase of the experiment.

At the beginning and at the end of the Experiment, you are asked to reply to a short questionnaire.

At the beginning of the Experiment, each participant is randomly assigned one of two possible roles. Half the participants will be assigned the role of Buyer; the other half will be assigned the role of Seller. You will remain in the same role you have been assigned throughout the experiment.

In each of Phase I, II and III and in each of their rounds you will be matched with a different participant randomly assigned to you. In Phase IV you will decide individually and independently of your role.

\section{Description of the task: Phase I}

In Phase I selling of a firm between a Seller, who owns the firm, and Buyer can take place. You will be told if you are Buyer or Seller, and will be matched with one of the other participant in the other role. For example, if you are selected as Buyer, then you will be randomly and anonymously matched with another participant who is a Seller.

The computer will randomly select the value of the firm among the following values: 5, 10, 15, 20, 25, 30, $35,40,45,50,55,60,65,70,75,80,85,90$ and 95 (all the values are equally likely). This value will be communicated only to the Seller. The Buyer will not learn the value of the firm selected randomly by the computer.

The Seller's evaluation of the firm is proportional to the value of the firm selected by the computer. This 
proportion will be randomly selected by the computer and can only take one of the following values: 10, 20, $30,40,50,60,70,80$ or 90 percent (all the values are equally likely). The Seller's evaluation is the value of the firm multiplied by the selected proportion. The proportion will be communicated to both, Buyer and Seller, whereas the value of the firm will be known only to the Seller. Do not worry: the software will provide the information on the decision screen, depending on your role, Seller or Buyer.

As an example, suppose that the computer selected a value of the firm equal to 90 and a proportion of 50 percent, so that the Seller's evaluation of the firm will be 45 , corresponding to 50 percent of 90 . In this case, the Seller will find on the screen of the computer that the value of the firm is 90, the proportion is 50 percent and that the Seller's evaluation is 45; the Buyer will find on the screen only the proportion of 50 percent. Another example: suppose that the computer selected a value of the firm equal to 90 and a proportion of 80 percent. In this case, the Seller's evaluation will be equal to 72, corresponding to 80 percent of 90 . In this case, the Seller will find on the screen of the computer that the value of the firm is 90, the proportion is 80 percent and that the Seller's evaluation is 72 ; the Buyer will find on the screen only the proportion of 80 percent.

The Seller sends a value message to the Buyer about the value of the firm, which can be either true or false. Therefore, the value message is not necessarily equal to the firm value nor to the Seller's evaluation of the firm. The message consists of an integer value between 0 and 100 .

After having received the message, the Buyer makes a take-it-or-leave-it offer to the Seller by proposing a price, an integer number between 0 and 100. When making this offer, the Buyer just knows the value message and by which proportion of the value the Seller evaluates the firm.

After having received the price offer of the Buyer, the Seller decides whether to accept it or not. If she accepts, the firm will be sold for the offered price to the Buyer. If she does not accept, no trade takes place. After the Seller has decided, the payoffs of Buyer and of Seller are calculated and individually communicated at the end of Phase I. These payoffs are calculated as explained below, and they are paid to all participants at the end of the experiment.
Calculation of the payoff in Phase I

The payoff of the unique round in Phase I does not depend on the value message and is calculated as follows:

If the Seller has accepted the offered price, the payoffs are:

- The Buyer earns the difference between the value of the firm and the accepted price

- The Seller earns the difference between the accepted price and the Seller's evaluation of the firm

An example: suppose that the firm value is equal to 45 and that the proportion of the firm value is 80 percent, so that the Seller's evaluation of the firm is 36 . Suppose the Buyer offers a price equal to 40 and that the Seller accepts it. In this case, the Buyer earns $45-40=5$, and the Seller earns $40-36=4$.

Another example: suppose that the firm value is equal to 45 and that the proportion of the firm value is 80 percent, so that the Seller's evaluation of the firm is 36. Suppose the Buyer offers a price equal to 55 and that the Seller accepts it. In this case, the Buyer earns $45-55=-10$, and the Seller earns $55-36=19$.

If the Seller does not accept the Buyer's offer, the payoffs are 0 for both Seller and Buyer.

\section{Description of the task: Phase II}

In Phase II, you will face for 30 rounds the same situation as in Phase I. As in the previous Phase, in each of the rounds you will be matched with a different participant randomly assigned to you.

The same instructions as in Phase I apply to Phase II, also the calculation of the payoffs.

The payment from this Phase will consist of the payoff of one of the 30 rounds randomly selected. For example, if round number five is selected, your payment for Phase II will be the payoff you earned in that round.

Calculation of the payoff in each round in Phase II

The payoff of each round in Phase II does not depend on the value message and is calculated as follows:

If the Seller has accepted the offered price, the payoffs are:

- The Buyer earns the difference between the value of the firm and the accepted price 
- The Seller earns the difference between the accepted price and the Seller's evaluation of the firm

An example: suppose that the firm value is equal to 45 and that the proportion of the firm value is 80 percent, so that the Seller's evaluation of the firm is 36 . Suppose the Buyer offer a price equal to 40, and that the Seller accepts it. In this case, the Buyer earns $45-40=5$, and the Seller earns $40-36=4$.

Another example: suppose that the firm value is equal to 45 and that the proportion of the firm value is 80 percent, so that the Seller's evaluation of the firm is 36. Suppose the Buyer offers a price equal to 55, and that the Seller accepts it. In this case, the Buyer earns $45-55=-10$, and the Seller earns $55-36=19$.

If the Seller does not accept the Buyer's offer, the payoffs are 0 for both Seller and Buyer.

\section{Description of the task: Phase III}

In Phase III, you will face for 12 rounds the same situation as in Phase I. As in the previous Phase, in each of the rounds you will be matched with a different participant randomly assigned to you.

The same instructions as in Phase I apply to Phase III.

At the beginning of the Phase, you will be asked if you prefer to be paid on the basis of the payoff of one of the 12 rounds randomly selected or on the basis of the average payoff of the 12 rounds. On the basis of your choice, the computer will calculate your payoff for this Phase.

Calculation of the payoff in each round in Phase III

The payoff of each round in Phase II does not depend on the value message and is calculated as follows:

If the Seller has accepted the offered price, the payoffs are:

- The Buyer earns the difference between the value of the firm and the accepted price

- The Seller earns the difference between the accepted price and the Seller's evaluation of the firm

An example: suppose that the firm value is equal to 45 and that the proportion of the firm value is 80 percent, so that the Seller's evaluation of the firm is 36 .
Suppose the Buyer offers a price equal to 40 and that the Seller accepts it. In this case, the Buyer earns $45-40=5$, and the Seller earns $40-36=4$.

Another example: suppose that the firm value is equal to 45 and that the proportion of the firm value is 80 percent, so that the Seller's evaluation of the firm is 36. Suppose the Buyer offers a price equal to 55, and that the Seller accepts it. In this case, the Buyer earns $45-55=-10$, and the Seller earns $55-36=19$.

If the Seller does not accept the Buyer's offer, the payoffs are 0 for both Seller and Buyer.

\section{Description of the task: Phase IV}

Phase IV consists of 10 rounds; during this Phase, you will not interact with other participants. During this phase, you are asked to choose between pairs of lotteries. In particular, in each round for each lottery pair you have to assess which one you would prefer to play.

At the end of the experiment, one round will be randomly selected for payment, and the computer will play on your screen the lottery that you have preferred in this round. The payment of Phase IV is given by the result of this lottery.

\section{Your final payment}

Your final payment will be displayed on the screen at the end of the experiment. It is determined as the sum of:

- Payoff from the unique round in Phase I (in euro)

- Payoff from one randomly selected round in Phase II (in euro)

- Payoff from EITHER one randomly selected round OR an average payment between 12 rounds from Phase III (in euro)

- Payoff from one randomly selected round in Phase IV (in euro)

- Participation fee.

\section{References}

Akerlof, G. A. (1970). The market for lemons: Quality uncertainty and the market mechanism. The Quarterly Journal of Economics, 84(3), 488-500. doi:10.2307/1879431.

Arellano, M., \& Bover, O. (1995). Another look at instrumental variable estimation of error component models. Journal of Econometrics, 68(1), 29-51. doi:10.1016/03044076(94)01642-D. 
Arentz, J., Sautet, F., \& Storr, V. (2013). Prior-knowledge and opportunity identification. Small Business Economics, 41, 461-478. doi:10.1007/s11187-012-9437-9.

Blundell, R., \& Bond, S. (1998). Initial conditions and moment restrictions in dynamic panel data models. Journal of Econometrics, 87(1), 115-143. doi:10.1016/S03044076(98)00009-8.

Bönte, W., \& Piegeler, M. (2013). Gender gap in latent and nascent entrepreneurship: Driven by competitiveness. Small Business Economics, 41, 961-987. doi:10.1007/ s11187-012-9459-3.

Brush, C. G. (1992). Research on women business owners: Past trends, a new perspective and future directions. Small Business: Critical Perspectives on Business and Management, 3, 1038-1070.

Camerer, C. F. (2003). Behavioral game theory: Experiments on strategic interaction. Princeton: Princeton University Press.

Casari, M., Ham, J. C., \& Kagel, J. H. (2007). Selection bias, demographic effects, and ability effects in common value auction experiments. The American Economic Review, 97(4), 1278. doi:10.1257/aer.97.4.1278.

Cooper, D. J., \& Kagel, J. H. (2013). Other-regarding preferences: A selective survey of experimental results. In J. H. Kagel \& A. E. Roth (Eds.), Handbook of experimental economics (Vol. 2). Princeton, NJ: Princeton University Press.

Crawford, V. (1998). A survey of experiments on communication via cheap talk. Journal of Economic Theory, 78(2), 286-298. doi:10.1006/jeth.1997.2359.

Croson, R., \& Gneezy, U. (2009). Gender differences in preferences. Journal of Economic literature. doi:10.1257/jel. 47.2.448.

Daly, M. (1991). The 1980s: A decade of growth in enterprise. Employment Gazette, 99, 109-134.

Di Cagno, D., Galliera, A., Güth, W., Pace, N., \& Panaccione, L. (2016). Make-up and suspicion in bargaining with cheap talk: An experiment controlling for gender and gender constellation. Theory and Decision, 80(3), 463-471. doi:10.1007/s11238-015-9497-9.

Dreber, A., \& Johannesson, M. (2008). Gender differences in deception. Economics Letters, 99(1), 197-199. doi:10. 1016/j.econlet.2007.06.027.

Erat, S., \& Gneezy, U. (2011). White lies. Management Science, 8(4), 723-733. doi:10.1287/mnsc.1110.1449.

Fischbacher, U. (2007). z-Tree: Zurich toolbox for ready-made economic experiments. Experimental Economics, 10(2), 171-178. doi:10.1007/s10683-006-9159-4.

Gneezy, U. (2005). Deception: The role of consequences. American Economic Review, 95(1), 384-394. doi:10.1257/ 0002828053828662.

Gneezy, U., Rockenbach, B., \& Serra-Garcia, M. (2013). Measuring lying aversion. Journal of Economic Behavior \& Organization, 93, 293-300. doi:10.1016/j.jebo.2013.03. 025 .

Greiner, B. (2004). The online recruitment system ORSEE 2.0-A guide for the organization of experiments in economics. In Working Paper Series in Economics (Vol. 10). University of Cologne, Department of Economics.

Güth, W., \& Kocher, M. G. (2014). More than thirty years of ultimatum bargaining experiments: Motives, variations, and a survey of the recent literature. Journal of Economic Behavior \& Organization, 108(C), 396-409. doi:10.1016/j. jebo.2014.06.006.

Harsanyi, J. C. (1967-1968). Games with incomplete information played by Bayesian players. Management Science, 14, 159-182 (Part I, doi:10.1287/mnsc.1040.0270), 320-334 (Part II, doi:10.1287/mnsc.14.5.320), 486-502 (Part III, doi:10.1287/mnsc.14.7.486).

Ham, J. C., \& Kagel, J. H. (2006). Gender effects in private value auctions. Economics Letters, 92(3), 375-382. doi:10. 1016/j.econlet.2006.03.024.

Houser, D., Vetter, S., \& Winter, J. (2012). Fairness and cheating. European Economic Review, 56(8), 1645-1655. doi:10.1016/j.euroecorev.2012.08.001.

Kagel, J. H., \& Levin, D. (2014). Auctions: A survey of experimental research. In J. H. Kagel \& A. E. Roth (Eds.), Handbook of experimental economics (Vol. 2). Princeton, NJ: Princeton University Press.

Kahneman, D. (2013). Thinking, fast and slow. New York: Farrar, Straus and Giroux.

Kartik, N. (2009). Strategic communication with lying costs. The Review of Economic Studies, 76(4), 1359-1395. doi:10.1111/j.1467-937X.2009.00559.

Loscocco, K. A., Robinson, J., Hall, R. H., \& Allen, J. K. (1991). Gender and small business success: An inquiry into women's relative disadvantage. Social Forces, 70(1), 65-85. doi:10.1093/sf/70.1.65.

Minniti, M., \& Nardone, C. (2007). Being in someone elses shoes: The role of gender in nascent entrepreneurship. Small Business Economics, 28, 223-238. doi:10.1007/ s11187-006-9017-y.

Ortmann, A., \& Tichy, L. (1999). Gender differences in the laboratory: Evidence from prisoner's dilemma games. Journal of Economic Behavior and Organization, 39(3), 327-339. doi:10.1016/S0167-2681(99)00038-4.

Posner, R. A. (2009). Antitrust law. Chicago: University of Chicago Press.

Rosa, P., Carter, S., \& Hamilton, D. (1996). Gender as a determinant of small business performance: Insights from a British study. Small Business Economics, 8(6), 463-478. doi:10.1007/BF00390031.

Sutter, M., Bosman, R., Kocher, M. G., \& van Winden, F. (2009). Gender pairing and bargaining - Beware the same sex!. Experimental Economics, 12(3), 318-331. doi:10. 1007/s10683-009-9217-9.

Samuelson, W. F., \& Bazerman, M. H. (1985). Negotiation under the winner's curse. Research in experimental economics, 3, 105-138.

Verheul, I., \& Thurik, R. (2001). Start-up capital: Does gender matter? Small Business Economics, 16, 329345.

Valley, K. L., Moag, J., \& Bazerman, M. H. (1998). A matter of trust: Effects of communication on the efficiency and distribution of outcomes. Journal of Economic Behavior and Organization, 34, 211-238. doi:10.1016/S01672681(97)00054-1.

Valley, K., Thompson, L., Gibbons, R., \& Bazerman, M. H. (2002). How communication improves efficiency in bargaining games. Games and Economic Behavior, 38, 127-155. doi:10.1006/game.2001.0855. 